\title{
1 Globally invariant metabolism but density-diversity mismatch in springtails
}

2 Anton M. Potapov ${ }^{1,2 *}$, Carlos A. Guerra ${ }^{3,4}$, Johan van den Hoogen ${ }^{5}$, Anatoly Babenko ${ }^{2}$, Bruno C. Bellini ${ }^{6}$, 3 Matty P. Berg ${ }^{7,8}$, Steven L. Chown ${ }^{9}$, Louis Deharveng ${ }^{10}$, L'ubomír Kováć ${ }^{11}$, Natalia A. Kuznetsova ${ }^{12}$, Jean-

4 François Ponge ${ }^{13}$, Mikhail B. Potapov ${ }^{12}$, David J. Russell ${ }^{14}$, Douglas Alexandre ${ }^{15}$, Juha M. Alatalo ${ }^{16}$, Javier 5 I. Arbea ${ }^{17}$, Ipsa Bandyopadhyay ${ }^{18}$, Verónica Bernava ${ }^{19}$, Stef Bokhorst ${ }^{7}$, Thomas Bolger ${ }^{20,21}$, Gabriela 6 Castaño-Meneses ${ }^{22}$, Matthieu Chauvat ${ }^{23}$, Ting-Wen Chen $^{24,1}$, Mathilde Chomel $^{25}$, Aimee T. Classen ${ }^{26}$,

7 Jerome Cortet $^{27}$, Peter Čuchta ${ }^{24}$, Ana Manuela de la Pedrosa ${ }^{25}$ Susana S. D. Ferreira $^{7}$, Cristina Fiera ${ }^{27}$, 8 Juliane Filser ${ }^{28}$, Oscar Franken ${ }^{7,8,85}$, Saori Fujiii ${ }^{29}$, Essivi Gagnon Koudji ${ }^{30}$, Meixiang Gao ${ }^{31}$, Benoit

9 Gendreau-Berthiaume ${ }^{32}$, Diego F. Gomez-Pamies ${ }^{33}$, Michelle Greve ${ }^{34}$, I. Tanya Handa ${ }^{30}$, Charlène

10 Heiniger $^{35}$, Martin Holmstrup ${ }^{36}$, Pablo Homet $^{37}$, Mari Ivask ${ }^{38}$, Charlene Janion-Scheepers ${ }^{39,4}$, Malte 11 Jochum $^{3,4}$, Sophie Joimel ${ }^{40}$, Bruna Claudia S. Jorge ${ }^{41}$, Edite Jucevica ${ }^{42}$, Luís Carlos Iuñes de Oliveira 12 Filho $^{43}$, Osmar Klauberg-Filho ${ }^{43}$, Dilmar Baretta ${ }^{44}$, Eveline J. Krab ${ }^{45,46}$, Annely Kuu ${ }^{47}$, Estevam C. A. de 13 Lima $^{48}$, Dunmei Lin ${ }^{49}$, Amy Liu ${ }^{9}$, Jing-Zhong Lu${ }^{1}$, María José Luciañez ${ }^{25}$, Michael T. Marx ${ }^{50}$, Matthew M. 14 McCary $^{51}$, Maria A. Minor ${ }^{52}$, Taizo Nakamori ${ }^{53}$, Ilaria Negrii ${ }^{54}$, Raúl Ochoa-Hueso ${ }^{55,56}$, José G. Palacios$15 \operatorname{Vargas}^{57}$, Melanie M. Pollierer ${ }^{1}$, Pascal Querner ${ }^{58,59}$, Natália Raschmanová ${ }^{11}$, Muhammad Imtiaz Rashid ${ }^{60}$, 16 Laura J. Raymond-Léonard ${ }^{30}$, Laurent Rousseau ${ }^{30}$, Ruslan A. Saifutdinov ${ }^{2}$, Sandrine Salmon ${ }^{61}$, Emma J. Sayer ${ }^{62,63}$, Nicole Scheunemann ${ }^{1,64}$, Cornelia Scholz ${ }^{59}$, Julia Seeber ${ }^{65,66}$, Yulia B. Shveenkova ${ }^{67}$, Sophya K. Stebaeva ${ }^{2}$, Maria Sterzynska ${ }^{68}$, Xin Sun ${ }^{69}$, Winda I Susanti ${ }^{1}$, Anastasia A. Taskaeva ${ }^{70}$, Madhav P.

Thakur $^{71}$, Maria A. Tsiafouli ${ }^{72}$, Matthew S. Turnbull ${ }^{73}$, Mthokozisi N. Twala ${ }^{34}$, Alexei V. Uvarov ${ }^{2}$, Lisa A. Venier $^{74}$, Lina A. Widenfalk ${ }^{75,76}$, Bruna R. Winck ${ }^{41}$, Daniel Winkler ${ }^{77}$, Donghui $\mathrm{Wu}^{78,79,80}$, Zhijing Xie ${ }^{78}$, Rui Yin ${ }^{81,82}$, Douglas Zeppelini ${ }^{83}$, Thomas W. Crowther ${ }^{5}$, Nico Eisenhauer ${ }^{3,81}$, Stefan Scheu ${ }^{1,84}$

${ }^{1}$ Johann Friedrich Blumenbach Institute of Zoology and Anthropology, University of Göttingen, Göttingen,

Germany. ${ }^{2}$ A.N. Severtsov Institute of Ecology and Evolution, Russian Academy of Sciences, Moscow, Russia.

${ }^{3}$ Experimental Interaction Ecology Group, German Centre for Integrative Biodiversity Research (iDiv) Halle- 
$30{ }^{8}$ Community and Conservation Ecology Group, Groningen Institute of Evolutionary Life Science, University of

31 Groningen, Amsterdam, the Netherlands. ${ }^{9}$ Securing Antarctica’s Environmental Future, School of Biological

32 Sciences, Monash University, Australia. ${ }^{10}$ ISYEB, Muséum National d'Histoire Naturelle, Paris, France.

$33{ }^{11}$ Department of Zoology, Institute of Biology and Ecology, Faculty of Science, Pavol Jozef Šafárik University

34 in Košice, košice, Slovakia. ${ }^{12}$ Institute of Biology and Chemistry, Moscow Pedagogical State University,

Moscow, Russia. ${ }^{13}$ Département Adaptations du Vivant, Muséum National d’Histoire Naturelle, Brunoy,

France. ${ }^{14}$ Department of Soil Zoology, Senckenberg Society for Nature Research, Görlitz, Germany.

${ }^{15}$ Department of Soil Science, Centre for Agriculture and Veterinary Science, Santa Catarina State University

University (UDUESC- Lages), Lages, SC, Brazil. ${ }^{16}$ Environmental Science Center, Qatar University, Doha,

Qatar. ${ }^{17}$ Department of Sciences, CEPA Camargo, Astillero, Spain. ${ }^{18}$ Visva Bharati University, Bengal, India.

${ }^{19}$ Administración de Parques Nacionales, Argentina. ${ }^{20}$ School of Biology and Environmental Science, University

College Dublin, Dublin, Ireland. ${ }^{21}$ Earth Institute, University College Dublin, Dublin, Ireland. ${ }^{22}$ Unidad

Multidisciplinaria de Docencia e Investigación, Facultad de Ciencias, Campus Juriquilla, Universidad Nacional

Autónoma de México, Querétaro, México. ${ }^{23}$ Normandie University - UNIROUEN, INRAE, ECODIV, Rouen,

France. ${ }^{24}$ Biology Centre of the Czech Academy of Sciences, Institute of Soil Biology, České Budějovice,

Czech Republic. ${ }^{25}$ Departmento de Biología (Zoología, Universidad Autónoma de Madrid, Spain. ${ }^{26}$ Department of Ecology \& Evolutionary Biology, University of Michigan, MI 48109. ${ }^{27}$ Institute of Biology Bucharest,

Romanian Academy, Romania. ${ }^{28} \mathrm{FB}$ 02, UFT, General and Theoretical Ecology, University of Bremen,

Bremen, Germany. ${ }^{29}$ Department of Forest Entomology, Forestry and Forest Products Research Institute,

Tsukuba, Japan. ${ }^{30}$ Département des Sciences Biologiques, Université du Québec à Montréal, Québec, Canada.

${ }^{31}$ Department of Geography and Spatial Information Techniques, Ningbo University, Ningbo, China.

${ }^{32}$ Département des Sciences Naturelles, Université du Québec en Outaouais, Québec, Canada. ${ }^{33}$ Instituto de

South Africa. ${ }^{35} \mathrm{HES}$-SO University of Applied Sciences and Arts Western Switzerland. ${ }^{36}$ Section of Terrestrial Agrobiología de Sevilla (IRNAS), Consejo Superior de Investigaciones Científicas (CSIC), Sevilla, Spain. 
do Sul, Porto Alegre, Brazil. ${ }^{42}$ Institute of Biology, University of Latvia, Riga, Latvia. ${ }^{43}$ Department of Soil

Science, Centre for Agriculture and Veterinary Science, Santa Catarina State University (UDESC-Lages),

Lages, SC, Brazil. ${ }^{44}$ Department of Animal Science, Santa Catarina State University (UDESC Oeste), Chapecó, of Natural History Görlitz, Görlitz, Germany. ${ }^{65}$ Institute for Alpine Environment, Eurac Research, Bozen, Italy. and Health, Institute of Urban Environment, Chinese Academy of Sciences, Xiamen, China. ${ }^{70}$ Institute of 
Forest Service, Natural Resources Canada, Sault Ste. Marie, Canada. ${ }^{75}$ Department of Ecology, Swedish University of Agricultural Sciences, Uppsala, Sweden. ${ }^{76}$ Greensway AB, Uppsala, Sweden. ${ }^{77}$ Institute of Wildlife Management and Wildlife Biology, University of Sopron, Sopron, Hungary. ${ }^{78}$ Key laboratory of Wetland Ecology and Environment, Northeast Institute of Geography and Agroecology, Chinese Academy of Sciences, Changchun 130102, China. ${ }^{79}$ Key Laboratory of Vegetation Ecology, Ministry of Education, Northeast Normal University, Changchun 130024, China. ${ }^{80}$ Jilin Provincial Key Laboratory of Animal Resource Conservation and Utilization, Northeast Normal University, Changchun 130117, China. ${ }^{81}$ Institute of Biology, Leipzig University, Leipzig, Germany. ${ }^{82}$ Community Department, Helmholtz Center for Environmental Research, Halle, Germany. ${ }^{83}$ Department of Biology, Paraiba State University, Brazil. ${ }^{84}$ Centre of Biodiversity and Sustainable Land Use, University of Göttingen, Göttingen, Germany. ${ }^{85}$ Department of Coastal Systems, Royal Netherlands Institute for Sea Research, Landsdiep 4, 't Horntje (Texel), 1797 SZ the Netherlands. *email: potapov.msu@gmail.com

Soil life supports the functioning and biodiversity of terrestrial ecosystems $\mathbf{s}^{1,2}$. Springtails (Collembola) are among the most abundant soil animals regulating soil fertility and flow of energy through above- and belowground food webs ${ }^{3-5}$. However, the global distribution of springtail diversity and density, and how these relate to energy fluxes remains unknown. Here, using a global dataset collected from 2,470 sites, we estimate total soil springtail biomass at 29 Mt carbon (threefold higher than wild terrestrial vertebrates ${ }^{6}$ ) and record peak densities up to 2 million individuals per $\mathbf{m}^{2}$ in the Arctic. Despite a 20-fold biomass difference between tundra and the tropics, springtail energy use (community metabolism) remains similar across the latitudinal gradient, owing to the increase in temperature. Neither springtail density nor community metabolism were predicted by local species richness, which was highest in the tropics, but comparably high in some temperate forests and even tundra. Changes in springtail activity may emerge from latitudinal gradients in temperature, predation $^{7,8}$, and resource limitation ${ }^{7,9,10}$ in soil communities. Contrasting temperature 
responses of biomass, diversity and activity of springtail communities suggest that

climate warming will alter fundamental soil biodiversity metrics in different directions,

potentially restructuring terrestrial food webs and affecting major soil functions.

121 Soil biodiversity is an essential component of every terrestrial habitat that affects nutrient

cycling, soil fertility and plant-soil feedbacks, among other ecosystem functions and

services $^{1,2,11}$. Soil functioning is jointly driven by multiple components of soil biota that are

closely interconnected, including plants, microorganisms, micro-, meso-, and macrofauna ${ }^{12,13}$.

Land use, human activities, and climate changes induce widespread and rapid changes in the

abundance, diversity, and activity of soil biota, altering functional connections and ecosystem-level processes in the terrestrial biosphere ${ }^{14}$. To understand, predict, and adapt to these changes, comprehensive knowledge about the global distribution of multiple soil biota components is urgently needed ${ }^{15,16}$.

130 With a growing understanding of the biogeography of microorganisms ${ }^{17}$, micro- ${ }^{18}$ and 131 macrofauna ${ }^{19}$, a critical knowledge gap is the global distribution of soil mesofauna.

132 Springtails (Collembola, Hexapoda) are among the most abundant groups of mesofauna and soil animals from the equator to polar regions ${ }^{4,5}$. They are mostly microbial feeders, but also graze on litter and are often closely associated with plant roots ${ }^{3,20}$. Through these trophic relationships, springtails affect the growth and dispersal of prokaryotes, fungi, and plants,

136 thereby supporting nutrient cycling via the transformation, degradation, and stabilisation of

137 organic matter ${ }^{5,21}$. Furthermore, springtails are a key food resource for soil- and surface-

138 dwelling predators ${ }^{3,5}$, thus occupying a central position in soil food webs and supporting

139 multitrophic biodiversity.

140 To assess different functional facets of biological communities, metrics such as population

141 density and biomass (reflecting carbon stocks), taxonomic and phylogenetic diversity 
142 (ensuring multifunctionality and stability), and metabolic activity (quantifying energy fluxes

143 and thus functional influence) are commonly used ${ }^{6,22-24}$. Soil biodiversity assessments have

144 found unexpected global hotspots in temperate regions for microorganisms (fungi and

145 prokaryotes $)^{17}$ and macrofauna (earthworms $)^{19}$, which are not in line with the common

146 latitudinal biodiversity gradient found in aboveground organisms ${ }^{25}$. Functional

147 complementarity principles ${ }^{23}$ suggest that diverse soil communities in temperate ecosystems

148 are able to support higher organismal densities and have a more efficient resource use (i.e.,

149 higher total activity) than at other latitudes. However, there are no global assessments of soil

150 animal metabolic activities. In contrast to expectations of complementarity principles,

151 previous studies on plants ${ }^{26,27}$ and microbes ${ }^{9,17}$ suggest that diversity and activity (represented

152 by respiration) do not co-vary at the global scale, probably because strong environmental

153 constraints limit this relationship. These discrepancies emphasize the need to investigate

154 relationships of multiple metrics of soil animal communities. Springtails are an ideal model

155 organism for exploring such relationships at a global scale, due to their ubiquity, functional

156 diversity and high local species richness ${ }^{3-5}$.

157 Current knowledge suggests that springtails are especially abundant and diverse in temperate

158 coniferous forests and tundra, but less diverse in polar regions ${ }^{24,28}$. Many springtails are

159 adapted to high and stable humidity, and sensitive to drought and temperature changes ${ }^{29,30}$.

160 Consequently, springtail density and diversity is likely to decrease with future climate

161 change, detrimentally affecting soil food webs and ecosystem functioning ${ }^{31}$. At the same

162 time, springtail densities are relatively high in urban areas and in agricultural fields ${ }^{32,33}$, so

163 global springtail biomass may be moderately affected by land-use changes worldwide.

164 Disentangling the roles of vegetation, climate, human disturbance, and other drivers of

165 various springtail community metrics will be critical to understand their contribution to soil

166 functioning under different global change scenarios ${ }^{15,18}$. 
167 Here, we report the joint projection of density, diversity, and metabolic activity of soil springtail communities at the global scale and test whether high species richness supports

169 increased density and total activity across springtail communities globally, or whether this

170 relationship is constrained by environmental and biotic controls. We further aimed (1) to

171 assess whether the global distribution of springtail diversity matches that of aboveground

172 biota or other soil animals; (2) to test how different metrics of springtail communities are

173 affected by climate and human activities; and (3) to quantify the global biomass of springtails

174 as a component of the global carbon stock. Using an extensive dataset of soil springtail

175 communities collected within the framework of the \#GlobalCollembola initiative ${ }^{5}(2,470$

176 sites and 43,601 samples across all continents; Fig. 1a), we show contrasting patterns across

177 soil biodiversity metrics at a global scale and demonstrate that springtails are among the most 178 functionally important and ubiquitous animals in the terrestrial biosphere.

179 Latitudinal gradient

180 To calculate total biomass and metabolism of each springtail community, we used recorded

181 population densities together with estimated individual body masses and metabolic rates.

182 Body masses and metabolic rates were derived from taxon-specific body lengths using mean annual soil temperature and allometric regressions (for calculations and parameter uncertainties see Methods). For the assessment of local species richness, we selected $70 \%$ of the sampling sites with taxonomically-resolved communities and calculated rarefaction curves to account for unequal sampling efforts. As such, our trends refer to local diversity

187 (hundreds of meters), but may not be representative of regional-level diversity ${ }^{34}$.

188 Springtail density varied c. 30-fold across latitudes (Fig. 1b), with maximum densities in tundra $\left(\right.$ median $=131,422$ individuals $\left.\mathrm{m}^{-2}\right)$ and minimum densities in tropical forests $(5,831$ individuals $\left.\mathrm{m}^{-2}\right)$ and agricultural ecosystems (3,438 individuals $\mathrm{m}^{-2}$; Fig. $\left.\mathrm{S} 2 ; \mathrm{n}=2,210\right)$. 
191 Springtail dry biomass followed the same trend, with c. 20-fold higher biomass in tundra

192 (median $\left.=3.09 \mathrm{~g} \mathrm{~m}^{-2}\right)$ compared to tropical agricultural and forest ecosystems (c. $0.16 \mathrm{~g} \mathrm{~m}^{-2}$ ),

193 due to a lower average community body mass in polar as opposed to temperate and tropical

194 ecosystems (Fig. 1d,f; Fig. S2; n = 2,053). These density and biomass estimates are in line

195 with earlier studies ${ }^{24}$ but cover wider environmental gradients. The difference in average

196 community body mass may be explained by lower proportion of large surface-dwelling

197 springtail genera in polar regions ${ }^{35}$.

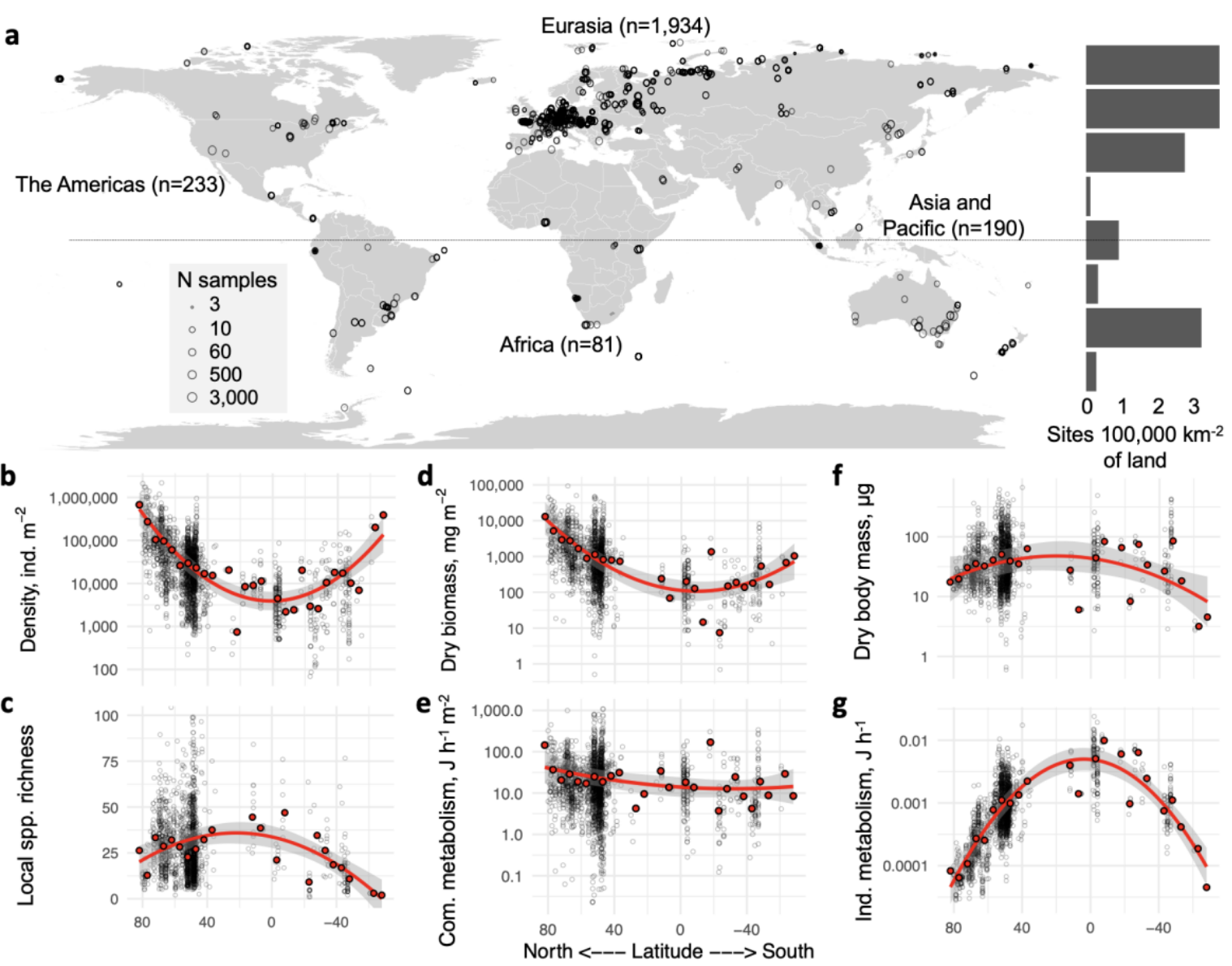

199 Fig. 1 | Sampling locations and latitudinal gradients in springtail community metrics. a,

200 Distribution of the 2,470 sampling sites (43,601 soil samples). The histogram shows the

201 number of sites in each 20-degree latitudinal belt, relative to the total land area in the belt. b-

$202 \mathrm{~g}$, Variation in density $(\mathrm{n}=2,210)$, local species richness $(\mathrm{n}=1,735)$, biomass, community metabolism, average body mass and average individual metabolism $(n=2,053)$ with latitude. 
204 Grey circles across panels show sampling sites; red points are averages for 5-degree

205 latitudinal belts; trends are illustrated with a quadratic function based on 5-degree averages.

206

207 Being dependent on temperature and body mass, average individual metabolism was

208 approximately 20 times higher in tropical than in polar ecosystems (Fig. 1g), which resulted

209 in similar community metabolism across the latitudinal gradient (Fig. 1e; total $\mathrm{n}=2,053$ ).

210 Hence, tropical springtail communities expend a similar amount of energy per unit time and

211 area as polar communities, despite having 20-fold lower biomass. This striking pattern

212 resembles aboveground ecosystem respiration, which also changes little across the global

213 temperature gradient ${ }^{27}$. High metabolic rates but low densities of springtail communities are

214 consistent with the high soil respiration rates and low litter accumulation in the tropics

215 compared to biomes at higher latitudes ${ }^{9,16}$. Litter removal is facilitated by soil animals, which

216 have to consume more food per unit biomass to meet their metabolic needs under high

217 tropical temperatures ${ }^{7}$ and thus enhance decomposition in wet and warm tropical

218 ecosystems ${ }^{10}$. This suggests that soil animal communities in the tropics are under strong

219 bottom-up control (by the amount and quality of litter), but also under strong top-down

220 control by predators, which likewise have to feed more at high temperatures ${ }^{7,8}$. By contrast,

221 polar communities have access to ample organic matter stocks ${ }^{16}$, are under weaker top-down

222 control $^{7,8}$, but their activity is constrained by the cold environment. The latitudinal gradient in

223 environmental and biotic controls may explain why community metabolism did not increase

224 as expected towards warm tropical ecosystems.

225 We found only weak latitudinal trends in local species richness, which was highest in tropical

226 forests $\left(\right.$ mean $=36.6$ species site $\left.^{-1}\right)$ and lowest in temperate agricultural $\left(19.5\right.$ species site $\left.{ }^{-1}\right)$

227 and grassland ecosystems (22.8 species site ${ }^{-1}$; Fig. 1c; Fig. S2). Generally, the similar local

228 diversity in different climates deviates from the latitudinal biodiversity gradients reported for 
aboveground and aquatic taxa $\mathrm{a}^{25,26}$ and corroborates the hypothesized mismatch between

230 above- and belowground biodiversity distributions ${ }^{36}$. This mismatch calls for explicit

231 assessments of soil biodiversity hotspots for monitoring and conservation of soil organisms ${ }^{15}$.

\section{Global distribution and its drivers}

233 To map the global distribution of springtail community metrics and uncover its drivers, we

234 pre-selected climatic, vegetation, soil, topographic and anthropogenic variables with known

235 ecological effects on springtails (Extended Data Fig. 9a). To perform a global extrapolation,

236 we used 22 of the pre-selected variables that were globally available and applied a random

237 forest algorithm to identify the strongest spatial associations of community parameters with

238 environmental layers ${ }^{18}$. To reveal the key driving factors of springtail communities, we ran a

239 path analysis with 12 non-collinear variables (Extended Data Fig. 9b). The European spatial

240 clustering in our data distribution (Fig. 1a), was taken in consideration with a continental-

241 scale validation in both analyses (see Methods).

242 At the global scale, species richness was not related to biomass (Pearson's $\mathrm{R}^{2}=0.02$ ) or

243 density (Pearson's $\mathrm{R}^{2}=0.03$; Fig. 2a). Our extrapolations revealed at least five types of

244 geographical areas with specific combinations of density and species richness patterns (Fig.

245 2a): (1) polar regions with very high densities and medium to high species richness such as

246 the Arctic; (2) temperate regions with medium densities and high species richness such as

247 mountainous and forested areas in Europe, Asia and North America; (3) temperate regions

248 with medium to high densities but moderate species richness such as arid temperate biomes

249 (e.g., dry grasslands); (4) temperate, subtropical and tropical arid ecosystems with low

250 densities and species richness such as semi-deserts and other arid regions; (5) tropical areas

251 with low densities but high species richness such as tropical forests and grasslands. Hotspots

252 of springtail community metabolism were observed across a range of different latitudes (Fig. 

communities at the global scale.

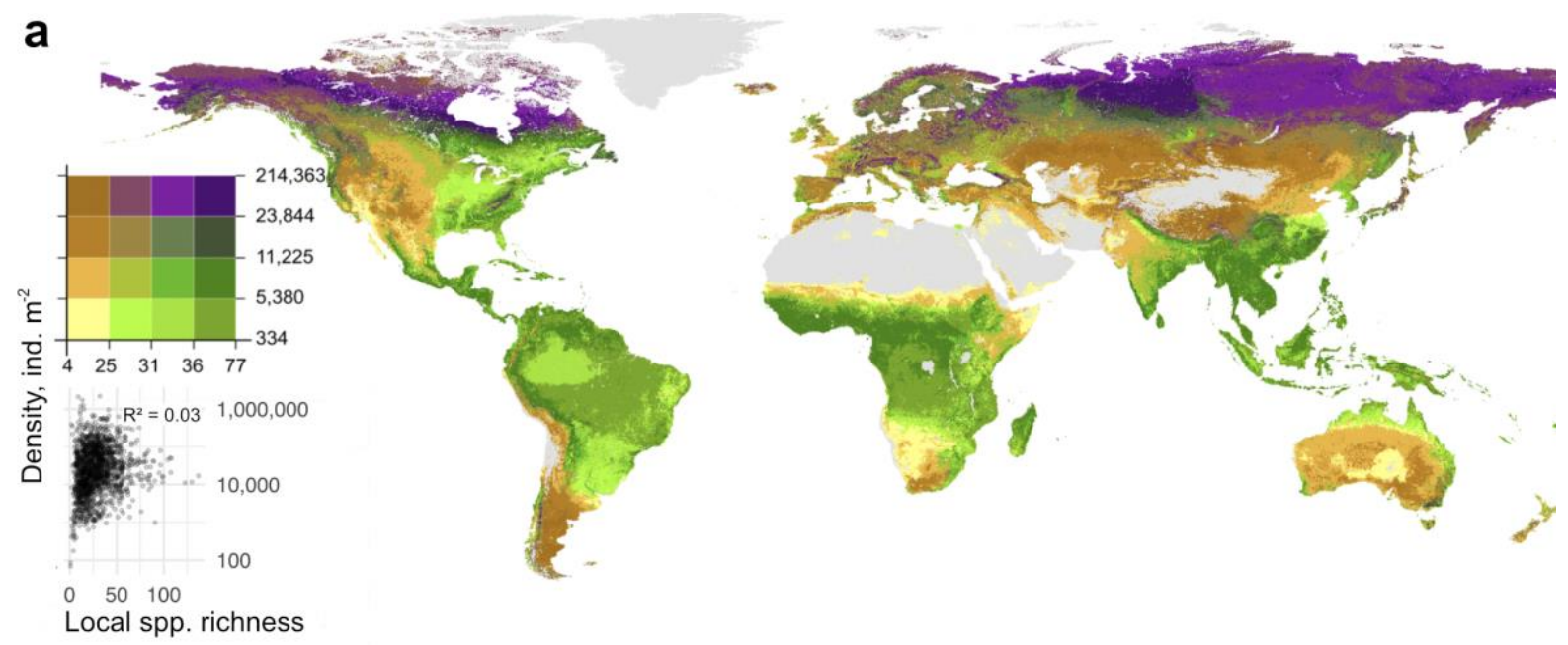

b
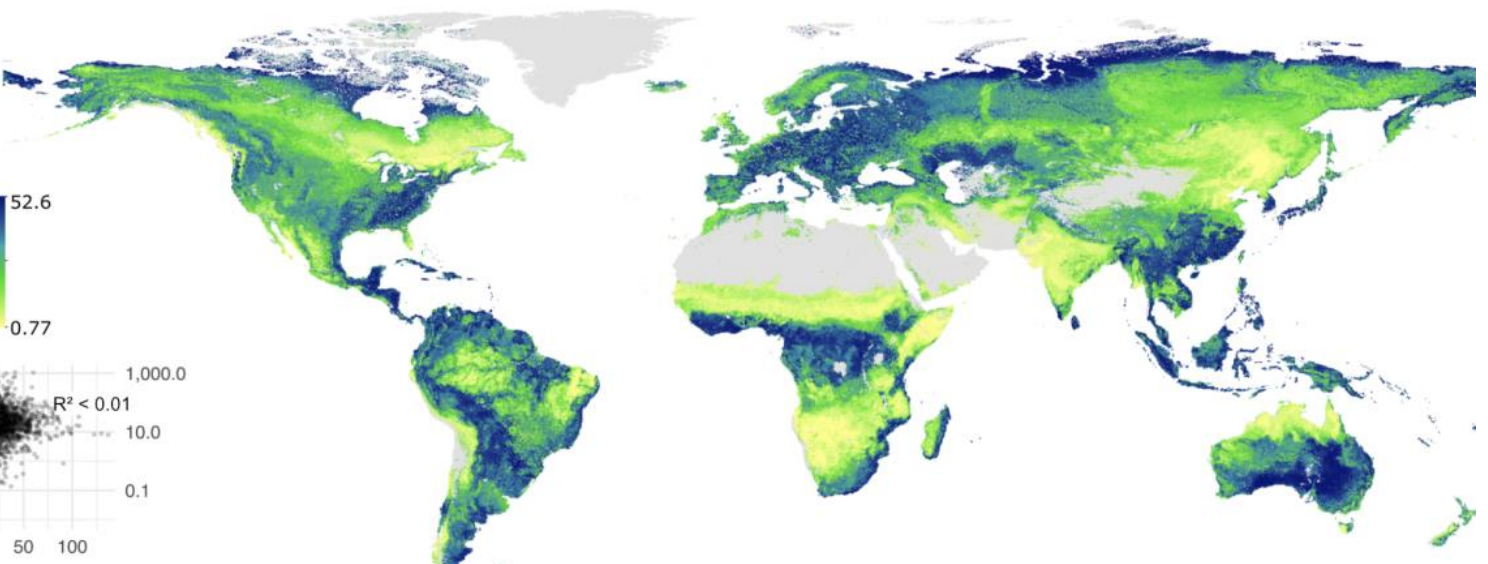

Fig. 2 | Global maps overlapping modelled springtail density and local species richness

(a) and community metabolism (b) in soil. In (a) colours distinguish areas with different

combinations of density and species richness, e.g., low density - low richness is given in

yellow and high density - high richness in violet. In (b) the colour gradient indicates

community metabolism, with potential hotspots shown in blue. All data were projected at the

$30 \operatorname{arcsec}$ (approximately $1 \mathrm{~km}^{2}$ ) pixel scale. Pixels below the extrapolation threshold are based on site-level data. 
266 Path analysis suggested that springtail density increases with latitude, NDVI (vegetation

267 richness), aridity index and at high soil $\mathrm{pH}$, but decreases with increasing mean annual

268 temperature and elevation (Fig. 3). The positive global relationship of density with the aridity

269 index was unexpected for physiologically moisture-dependent animals such as springtails ${ }^{29}$,

270 but was also observed in nematodes ${ }^{18}$ and is probably due to the low amount of precipitation

271 in circumpolar climates and very few data from desert sites. Density and biomass of

272 springtails increased with precipitation within the tropical zone (Extended Data Fig. 8).

273 Similar to patterns for earthworms ${ }^{19}$, soil properties had less evident linear effects on

274 springtail density than climate at the global scale. However, the relationships of density with

275 soil $\mathrm{pH}$ and organic carbon content were hump-shaped, suggesting that intermediate values of

276 these parameters are optimal for springtails (Extended Data Fig. 8), which is also observed

277 for nematodes ${ }^{18}$. Existing evidence points to soil properties as key drivers of microfauna

278 (nematodes) $^{6}$, climate as a key driver of macrofauna (earthworms) ${ }^{7}$ and a combination of both 279 as drivers of mesofauna (springtails) at the global scale.

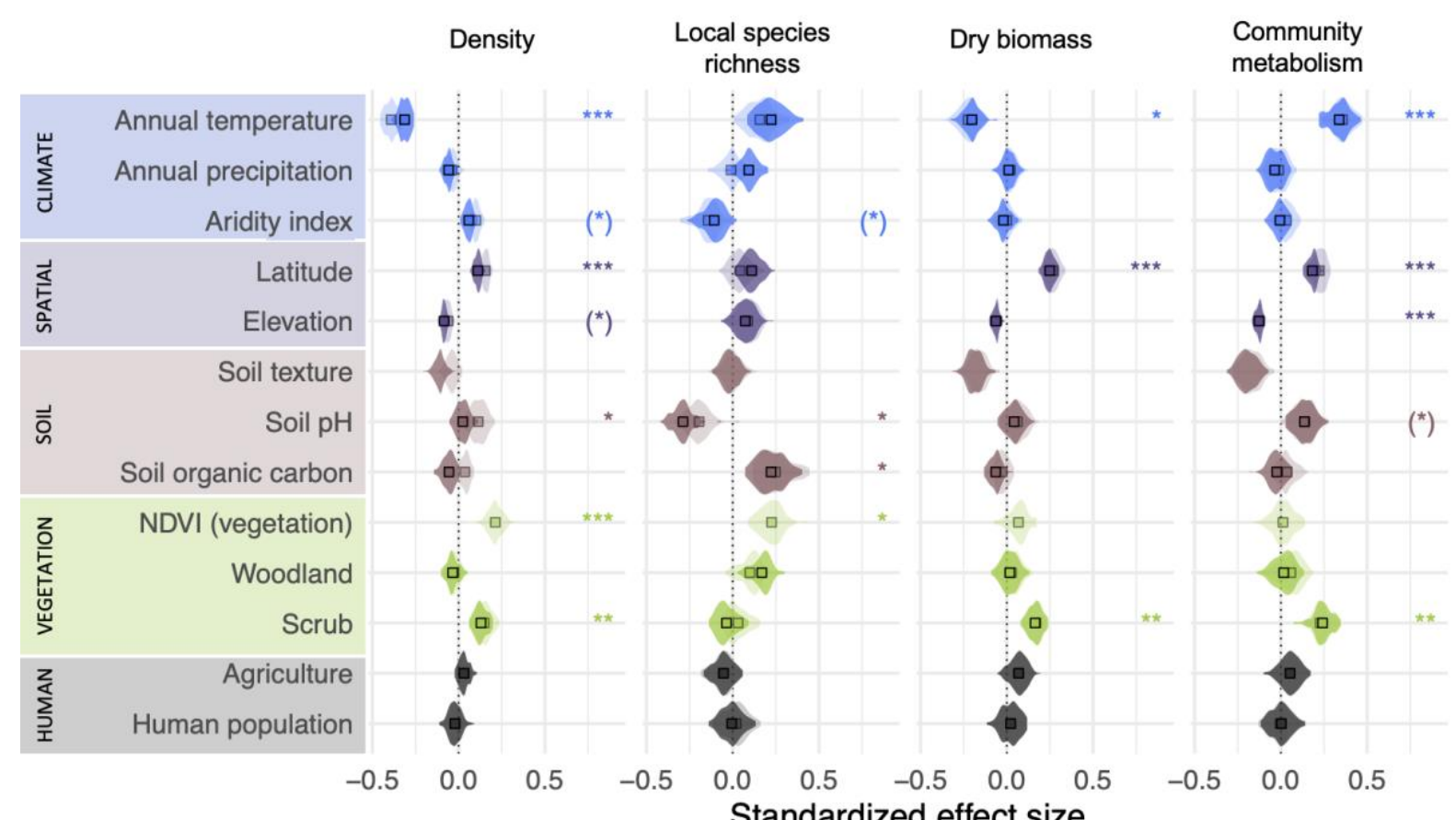


Fig. 3 | Environmental drivers of springtail communities at the global scale. Standardized effects from path analysis are shown for density $\left(R^{2}=0.36 \pm 0.01, n=723\right.$ per iteration), local species richness $\left(R^{2}=0.20 \pm 0.02, n=352\right)$, biomass $\left(R^{2}=0.40 \pm 0.02, n=568\right)$ and community metabolism $\left(\mathrm{R}^{2}=0.17 \pm 0.02, \mathrm{n}=533\right)$. Mean values (squares) and data distribution (violins) are shown. Asterisks denote factors with a significant direct effect ( $\mathrm{p}<$ $0.05)$ on a given springtail community metric for $>25 \%^{(*)},>50 \%^{*},>75 \%^{* *}$ and $>95 \%^{* * *}$ of iterations.

Springtail density and biomass were lower in woodlands, grasslands and agricultural sites in comparison to scrub-dominated landscapes (Fig. 3). In contrast to previous global assessments of soil animal biodiversity ${ }^{18,19}$, tundra was extensively sampled in our dataset (n $=253$; Fig. 1a), and densities $>1$ million individuals per square meter were recorded at 12 independent sites. The high species richness of tundra communities (Fig. 2a), suggests a long evolutionary history of springtails in cold climates; indeed, they are currently the most taxonomically represented group of terrestrial arthropods in the Arctic ${ }^{35}$ and the Antarctic ${ }^{37}$. Tundra remains under snow cover for most of the year, flourishing during summer when high springtail densities were recorded. During winter, springtails survive under the snow using remarkable adaptations to subzero temperatures (dehydration ${ }^{38}$ and 'supercooling ${ }^{38}$ ).

300 Importantly, tundra soils contain a major proportion of the total soil organic matter and 301 microbial biomass stored in the terrestrial biosphere ${ }^{16}$. As climate warming alters carbon cycling in the tundra ${ }^{39}$, longer active periods of springtails could accelerate soil carbon

303 release to the atmosphere in polar regions ${ }^{40}$.

304 Across tropical ecosystems in the Amazon basin, equatorial Africa and Southeast Asia, low 305 density and biomass of springtails were recorded and extrapolated (Fig. 2a, Extended Data 
306 Figs. 4 and 6). Mesofauna in general have low abundances in tropical ecosystems, where the

307 litter layer is shallow and larger soil-associated invertebrates, such as earthworms, termites

308 and ants, play a more important role ${ }^{24}$. Our study supports this trend also found in recent

309 global assessments of other soil invertebrates ${ }^{18,19,41}$. However, considering the high mass-

310 specific metabolism of springtails and high predation rates in tropical communities ${ }^{7,8,22}$, a

311 quantitative comparison of energy flows and stocks across latitudes and groups of soil fauna

312 is needed.

313 Interestingly, we found no pronounced influence of agriculture and human population on

314 springtail communities at the global scale; agriculture tended to have a positive impact on

315 biomass but a negative impact on species richness (Fig. 3). Agricultural sites had similar

316 springtail densities compared to woodlands and grasslands in the temperate zone (ca. $15-25 \mathrm{k}$

317 individuals $\mathrm{m}^{-2}$; Extended Data Fig. 3), which may be explained by large variation in

318 management within each of these habitat types. Some springtail species effectively survive in

319 agricultural fields ${ }^{33}$, where they are involved in nutrient cycling and serve as biocontrol

320 agents by grazing on pathogenic fungi ${ }^{42}$ and supporting arthropod predators ${ }^{43}$. Springtails are

321 also commonly found in urban areas ${ }^{32}$. However, the negative trend in species richness at

322 human-modified sites suggests that intensive land use may reduce springtail diversity, which

323 is indeed often recorded ${ }^{32,33,44}$.

324 The only variable that was positively associated with both density and local species richness

325 of springtails, was NDVI (as a proxy for vegetation richness), reinforcing the close

326 connection between springtail communities and the vegetation ${ }^{20}$. Overall, high local species

327 richness was predicted in warm, acidic woodlands with high soil organic carbon stocks (Fig.

328 3) and geospatial extrapolation emphasized tropical regions and some boreal forests in North

329 America and Eurasia as springtail diversity hotspots (Extended Data Fig. 5). In our dataset,

330 sites with the highest extrapolated local species richness (i.e., >100 species) were located in 
331 European woodlands (Czech Republic, Slovakia). However, this picture may be biased by the

332 historical clustering of taxonomic expertise in Europe ${ }^{5}$. Outside Eurasia, species-rich sites

333 (i.e. 60-80 species) were located in Vietnamese monsoon forests and some Brazilian

334 rainforests, but $70-90 \%$ of species in tropical communities remain undescribed ${ }^{45,46}$. Thus,

335 despite low springtail density, tropical forests contribute substantially to global springtail

336 diversity but the full extent of this contribution is unknown.

337 Our extrapolations suggest that there are c. $2 \times 10^{18}$ soil springtails globally and their total

338 biomass comprises c. 29 Mt C (c. 200 Mt fresh weight), with respiration of c. $16 \mathrm{Mt} \mathrm{C}$ month $^{-}$

$339{ }^{1}$ (which is c. $0.2 \%$ of the global soil respiration ${ }^{9}$ ). Our biomass estimates are very similar to

340 the global estimated biomass of nematodes (c. $31 \mathrm{Mt} \mathrm{C}^{18}$ ), but lower than that of earthworms

341 (c. $200 \mathrm{Mt} \mathrm{C}^{19}$ ), and exceeding by far that of all wild terrestrial vertebrates (c. $\left.9 \mathrm{Mt} \mathrm{C}\right)^{6}$,

342 demonstrating that springtails are among the most abundant and ubiquitous animals on Earth.

343 Overall, our global dataset on soil springtail communities synthesized the work of soil

344 zoologists across the globe. It presents another milestone towards understanding the

345 functional composition of global soil biodiversity. Being highly abundant in polar regions

346 and some human-modified landscapes, springtails are facing two main global change

347 frontiers: warming in the polar regions, and land-use change and urbanization in temperate

348 and tropical regions. While the global abundance and biomass of springtails may decline with

349 climate warming in the coming decades, their global activity may remain unchanged. The

350 global diversity of springtails will depend on the balance between anthropogenic transformations and conservation efforts of biomes worldwide. 
1. FAO, ITPS, GSBI, SCBD \& EC. State of knowledge of soil biodiversity Status, challenges and potentialities, Report 2020. (FAO, 2020). doi:10.4060/cb1928en.

2. Bardgett, R. D. \& van der Putten, W. H. Belowground biodiversity and ecosystem functioning. Nature 515, 505-511 (2014).

3. Rusek, J. Biodiversity of Collembola and their functional role in the ecosystem. Biodiversity and Conservation 7, 1207-1219 (1998).

4. Hopkin, S. P. Biology of springtails: (Insecta: Collembola). (Oxford Science Publications, 1997).

5. Potapov, A. et al. Towards a global synthesis of Collembola knowledge - challenges and potential solutions. Soil Organisms 92, 161-188 (2020).

6. Bar-On, Y. M., Phillips, R. \& Milo, R. The biomass distribution on Earth. Proceedings of the National Academy of Sciences 115, 6506-6511 (2018).

7. Rall, B. C. et al. Universal temperature and body-mass scaling of feeding rates. Philosophical Transactions of the Royal Society B: Biological Sciences 367, 2923-2934 (2012).

8. Roslin, T. et al. Higher predation risk for insect prey at low latitudes and elevations. Science 356, 742-744 (2017).

9. Huang, N. et al. Spatial and temporal variations in global soil respiration and their relationships with climate and land cover. Science Advances 6, eabb8508 (2020).

10. Wall, D. H. et al. Global decomposition experiment shows soil animal impacts on decomposition are climate-dependent. Global Change Biology 14, 2661-2677 (2008).

11. Handa, I. T. et al. Consequences of biodiversity loss for litter decomposition across biomes. Nature 509, 218-221 (2014).

12. Wagg, C., Bender, S. F., Widmer, F. \& van der Heijden, M. G. A. Soil biodiversity and soil community composition determine ecosystem multifunctionality. Proceedings of the National Academy of Sciences 111, 5266-5270 (2014). across biomes. Nature Ecology \& Evolution 4, 210-220 (2020). 
14. Geisen, S., Wall, D. H. \& van der Putten, W. H. Challenges andopportunities for soil biodiversity in the Anthropocene. Current Biology 29, R1036-R1044 (2019).

15. Guerra, C. A. et al. Tracking, targeting, and conserving soil biodiversity. Science 371, 239-241 (2021).

16. Crowther, T. W. et al. The global soil community and its influence on biogeochemistry. Science 365, (2019).

17. Bahram, M. et al. Structure and function of the global topsoil microbiome. Nature 560, 233-237 (2018).

18. van den Hoogen, J. et al. Soil nematode abundance and functional group composition at a global scale. Nature (2019) doi:10.1038/s41586-019-1418-6.

19. Phillips, H. R. P. et al. Global distribution of earthworm diversity. Science 366, 480-485 (2019). theory of ecology. Ecology 85, 1771-1789 (2004).

23. Hooper, D. U. et al. Effects of biodiversity on ecosystem functioning: A consensus of current knowledge. Ecological Monographs 75, 3-35 (2005).

24. Petersen, H. \& Luxton, M. A comparative analysis of soil fauna populations and their role in decomposition processes. Oikos 39, 288-388 (1982).

25. Hillebrand, H. On the Generality of the Latitudinal Diversity Gradient. The American Naturalist 163, 192-211 (2004).

26. Kreft, H. \& Jetz, W. Global patterns and determinants of vascular plant diversity. Proceedings of the National Academy of Sciences 104, 5925-5930 (2007). physiology and ecosystem paradoxes: insights from metabolic scaling theory. Global Change Biology 13, 591-609 (2007). 
407

408

409

410

411

412

413

414

415

416

417

418

419

420

421

422

423

424

425

426

427

428

429

430

431

432

433

28. Fierer, N., Strickland, M. S., Liptzin, D., Bradford, M. A. \& Cleveland, C. C. Global patterns in belowground communities. Ecology Letters 12, 1238-1249 (2009).

29. Kærsgaard, C. W., Holmstrup, M., Malte, H. \& Bayley, M. The importance of cuticular permeability, osmolyte production and body size for the desiccation resistance of nine species of Collembola. Journal of Insect Physiology 50, 5-15 (2004).

30. Janion-Scheepers, C. et al. Basal resistance enhances warming tolerance of alien over indigenous species across latitude. Proceedings of the National Academy of Sciences 115, 145-150 (2018).

31. Peguero, G. et al. Fast attrition of springtail communities by experimental drought and richnessdecomposition relationships across Europe. Global Change Biology 25, 2727-2738 (2019).

32. Joimel, S. et al. Urban and industrial land uses have a higher soil biological quality than expected from physicochemical quality. Science of The Total Environment 584-585, 614-621 (2017).

33. Filser, J., Mebes, K.-H., Winter, K., Lang, A. \& Kampichler, C. Long-term dynamics and interrelationships of soil Collembola and microorganisms in an arable landscape following land use change. Geoderma 105, 201-221 (2002).

34. Phillips, H. R. et al. Response to Comment on "Global distribution of earthworm diversity". Science 371, (2021).

35. Babenko, A. B. The structure of springtail fauna (Collembola) of the Arctic. Entomological Review 85, 878-890 (2005).

36. Cameron, E. K. et al. Global mismatches in aboveground and belowground biodiversity. Conservation Biology (2019).

37. Baird, H. P., Janion-Scheepers, C., Stevens, M. I., Leihy, R. I. \& Chown, S. L. The ecological biogeography of indigenous and introduced Antarctic springtails. Journal of Biogeography 46, 1959-1973 (2019).

38. Sørensen, J. G. \& Holmstrup, M. Cryoprotective dehydration is widespread in Arctic springtails. Journal of Insect Physiology 57, 1147-1153 (2011).

39. Box, J. E. et al. Key indicators of Arctic climate change: 1971-2017. Environmental Research Letters 14, 045010 (2019). 
40. Sørensen, L. I., Holmstrup, M., Maraldo, K., Christensen, S. \& Christensen, B. Soil fauna communities and microbial respiration in high Arctic tundra soils at Zackenberg, Northeast Greenland. Polar Biology 29, 189-195 (2006).

41. Johnston, A. S. A. \& Sibly, R. M. Multiple environmental controls explain global patterns in soil animal communities. Oecologia 192, 1047-1056 (2020).

42. Goncharov, A. A. et al. Detrital subsidy alters the soil invertebrate community and reduces infection of winter wheat seedlings by Fusarium wilt. Applied Soil Ecology 163, 103914 (2021).

43. von Berg, K., Thies, C., Tscharntke, T. \& Scheu, S. Changes in herbivore control in arable fields by detrital subsidies depend on predator species and vary in space. Oecologia 163, 1033-1042 (2010).

44. Tsiafouli, M. A. et al. Intensive agriculture reduces soil biodiversity across Europe. Global Change Biology 21, 973-985 (2015).

45. Shveenkova, Y. Springtail communities (Collembola, Hexapoda). in Structure and Functions of Soil Communities of a Monsoon Tropical Forest (Cat Tien National Park, southern Vietnam) (ed. Tiunov, A. V.) 131-147 (KMK Scientific Press, 2011).

46. Deharveng, L. \& Bedos, A. Factors influencing diversity of soil Collembola in a tropical mountane forest (Doi Inthanon, Northern Thailand). in Soil biota, nutrient cycling and farming systems (eds. Paoletti, M. G., Foissner, W. \& Coleman, D. C.) (Lewis Publishers, 1993).

\section{Methods}

Data reporting. The data underpinning this study is a compilation of existing datasets and therefore, no statistical methods were used to predetermine sample size, the experiments were not randomized and the investigators were not blinded to allocation during experiments and outcome assessment. The measurements were taken from distinct samples, repeated measurements from the same sites were averaged. 
459 Data acquisition. Data were primarily collected from individual archives of contributing co-

460 authors. Both published and unpublished data were collected, using raw data whenever

461 possible entered into a common template. In addition, data available from Edaphobase ${ }^{47}$ was

462 included. The following minimum set of variables was collected: collectors, collection

463 method (including sampling area and depth), extraction method, identification precision and

464 resources, collection date, latitude and longitude, vegetation type (generalized as grassland,

465 scrub, woodland, agriculture and 'other' for the analysis), and abundances of springtail taxa

466 found in each soil sample (or sampling site). Underrepresented geographical areas (Africa,

467 South America, Australia and Southeast Asia) were specifically targeted by a literature search

468 in the Web of Science database using the keywords 'springtail' or 'Collembola', 'density' or

469 'abundance' or 'diversity', and the region of interest; data were acquired from all found

470 papers if the minimum information listed above was provided. In total, 363 datasets

471 comprising 2,783 sites were collected and collated into a single dataset (Extended Data Fig.

$4721)$.

473 Calculation of community parameters. Community parameters were calculated at the site

474 level. Here, we defined a site as a locality that hosts a defined springtail community, is

475 covered by a certain vegetation type and has a maximum spatial extent (diameter) of several

476 hundred meters, making species co-occurrence and interactions plausible. To calculate

477 density, numerical abundance in all samples was averaged and recalculated per square meter

478 using the sampling area. Springtail communities were assessed predominantly during active

479 vegetation periods (i.e., spring, summer and autumn in temperate and boreal biomes, and

480 summer in polar biomes). Our estimations of community parameters therefore refer to the

481 most favourable conditions (peak yearly densities). This seasonal sampling bias is likely to

482 have little effect on our conclusions, since most springtails survive during cold periods ${ }^{38,48}$. 
483 Finally, we used mean annual temperatures ${ }^{49}$ to estimate the seasonal mean community

484 metabolism (described below).

485 All data analyses were conducted in R v. 4.0.2 ${ }^{50}$ with RStudio interface v. 1.4.1103 (RStudio,

486 PBC), unless otherwise mentioned. To calculate local species richness, we used data

487 identified to species or morphospecies level. Since the sampling effort varied among studies,

488 we extrapolated species richness using rarefaction curves based on individual samples with

489 the Chao estimator ${ }^{51}$ in the vegan package $^{52}$. For some sites, sample-level data were not

490 available in the original publications, but an extensive sampling effort was made. In such

491 cases, we predicted extrapolated species richness based on the completeness (ratio of

492 observed to extrapolated richness) recorded at sites where sample-level data were available

493 (only sites with 5 or more samples were used for the prediction). We built a binomial model

494 to predict completeness in sites where no sample-level data were available (435 sites in

495 Europe, 15 in Australia, 6 in South America, 4 in Asia, and 3 in Africa) using latitude and the

496 number of samples taken at a site as predictors.

497 To calculate biomass, we first cross-checked all taxonomic names with the collembola.org

498 checklist ${ }^{53}$ using fuzzy matching algorithms (fuzzyjoin $\mathrm{R}$ package ${ }^{54}$ ) to align taxonomic

499 names and correct typos. Then we merged taxonomic names with a dataset on body lengths

500 compiled from the BETSI database ${ }^{55}$, a personal database of Matty P. Berg, and additional

501 expert contributions. We used average body lengths for the genus level (body size data on

502432 genera) since data at the species level were not available for many species and

503 morphospecies, and species within most springtail genera had similar body size ranges. Dry

504 and fresh body masses were calculated from body length using a set of group-specific length-

505 mass regressions (Extended Data Table 1) ${ }^{56,57}$ and the results of different regressions applied

506 to the same morphogroup were averaged. Dry mass was recalculated to fresh mass using

507 corresponding group-specific coefficients ${ }^{56}$. We used fresh mass to calculate individual 
metabolic rates ${ }^{58}$ and account for the mean annual topsoil $(0-5 \mathrm{~cm})$ temperature at a given site $^{59}$. Group-specific metabolic coefficients for insects (including Collembola) were used for the calculation: normalization factor (i0) $\ln (21.972)\left[\mathrm{J} \mathrm{h}^{-1}\right]$, allometric exponent (a) 0.759 , and

511 activation energy (E) $0.657[\mathrm{eV}]^{58}$. Community-weighted (specimen-based) mean individual

512 dry masses and metabolic rates were calculated for each sample and then averaged by site

513 after excluding $10 \%$ of maximum and minimum values as outlier samples with small

514 sampling areas, which have a high probability of randomly including large individuals. To

515 calculate site-level biomasses and community metabolism, we summed masses or metabolic

516 rates of individuals, averaged them across samples, and recalculated them per unit area $\left(\mathrm{m}^{2}\right)$.

517 Parameter uncertainties. Our biomass and community metabolism approximations contain

518 several assumptions and ignore latitudinal variation in body sizes within taxonomic groups ${ }^{60}$.

519 Nevertheless, latitudinal differences in springtail density (30-fold), environmental

520 temperature (from -17.0 to $+27.6^{\circ} \mathrm{C}$ ), and genus-level community compositions (there are

521 only few common genera among polar regions and the tropics) ${ }^{53}$ are higher than the uncertainties introduced by indirect parameter estimations, which allowed us to detect global trends. Although most springtails are concentrated in the litter and uppermost soil layers ${ }^{24}$,

524 their vertical distribution depends on the particular ecosystem ${ }^{61}$. Since sampling methods are usually ecosystem-specific (i.e. sampling is done deeper in soils with developed organic

526 layers), we treated the methods used by the original data collectors as representative of a

527 given ecosystem. Under this assumption, we might have underestimated the number of springtails in soils with deep organic horizons, so our global estimates are conservative and we would expect true global density and biomass to be slightly higher. To minimize these

530 effects, we excluded sites where the estimations were likely to be unreliable (see data

531 selection below). 
532 Data selection. Only data collection methods allowing for area-based recalculation (e.g.

533 Tullgren or Berlese funnels) were used for analysis. Data from artificial habitats, coastal

534 ecosystems, caves, canopies, snow surfaces, and strong experimental manipulations beyond

535 the bounds of naturally occurring conditions were excluded (Extended Data Fig. 1). To

536 ensure data quality, we performed a two-step quality check: technical selection and expert

537 evaluation. Collected data varied according to collection protocols, such as sampling depth

538 and the microhabitats (layers) considered. To technically exclude unreliable density

539 estimations, we explored data with a number of diagnostic graphs (see Supplementary Data

540 Cleaning Protocol) and filtered it, excluding the following: (1) All woodlands where only soil

541 or only litter was considered; (2) All scrub ecosystems where only ground cover (litter or

542 mosses) was considered; (3) Agricultural sites in temperate zones where only soil with

543 sampling depth $<10 \mathrm{~cm}$ was considered. Additionally, $10 \%$ of the lowest values were

544 individually checked and excluded if density was unrealistically low for the given ecosystem

545 (outliers with density over three times lower than 1\% percentile within each ecosystem type).

546 In total, 237 sites were excluded from density, and 394 sites from biomass, and community

547 metabolism analyses based on these criteria. For the local species richness estimates, we

548 removed all extrapolations based on sites with fewer than three samples and no

549 (morpho)species identifications (647 sites; Extended Data Fig. 1).

550 Data expert evaluation. We performed manual expert evaluation of every contributed

551 dataset. Evaluation was done by an expert board of springtail specialists, each with extensive

552 research experience in a certain geographic area. Each dataset was scored separately for

553 density and species richness as either trustworthy, acceptable, or unreliable. Density

554 estimation quality was assessed using information about the sampling and extraction method

555 and the density estimation itself. Species richness estimation quality was assessed using

556 information about the identification key, experience of the person who identified the material, 
species (taxa) list, and the species richness estimation itself. Based on the expert opinions, unreliable estimates of density (together with biomass and community metabolism) and species richness were excluded (Extended Data Fig. 1). The resulting final dataset included 2,470 sites and 43,601 samples $^{62}$ with a median of six samples collected at each site. The dataset comprised 2,210 sites with density estimation (69-2,181,600 individuals $\left.\mathrm{m}^{-2}\right), 2,053$ sites with mean fresh body mass $(1.8-3,110 \mu \mathrm{g})$, mean metabolic rate $\left(0.028-2.4 \mathrm{~mJ} \mathrm{~h}^{-1}\right)$, dry biomass $\left(0.5-92,943 \mathrm{mg} \mathrm{m}^{-2}\right)$, fresh biomass $\left(1.6-277,028 \mathrm{mg} \mathrm{m}^{-2}\right)$ and community metabolism estimations $\left(0.03\right.$ - $\left.999.68 \mathrm{~J} \mathrm{~h}^{-1}\right)$, and 1,735 sites with local species richness estimation (1 - 136.7 species; Extended Data Figs. 1 and 2).

Data transformation. All parameters except for extrapolated local species richness were highly skewed (e.g., density had a global median of 21,016 individuals $\mathrm{m}^{-2}$ and a mean of 60,454 individuals $\mathrm{m}^{-2}$ ) and we applied $\log _{10}$-transformation prior to analysis. This greatly improved the fit of all statistical analyses.

570 Latitudinal and ecosystem trends. To explore changes in springtail communities with

571 latitude, we sliced the global latitudinal gradient into 5-degree bins and calculated average parameters across sites in each bin after trimming to ensure the same statistical weight for each latitudinal bin while plotting the gradient. The latitudinal gradient was plotted with ggplot $2^{63}$, and quadratic smoothers were used to illustrate trends. Mean parameters of springtail communities were compared across ecosystem types using a linear model and 576 multiple comparisons with the Tukey HSD test using HSD.test in the agricolae package ${ }^{64}$.

577 Habitats were classified according to the vegetation types. Climates were classified as polar 578 (beyond the polar circles, i.e., more than 66.5 and less than -66.5 degrees), temperate (from the polar circles to the tropics of Capricorn/Cancer, i.e. to 23.5 and -23.5 degrees) and

580 tropical (in between 23.5 and -23.5 degrees). Habitats and climates were combined to

581 produce ecosystem types. For the analysis, only well-represented ecosystem types were 
retained: polar scrub $(n=253)$, polar grassland $(n=39)$, polar woodland $(n=28)$, temperate

Fig. 3).

586 Selection of environmental predictors. To assess the drivers of global distributions of

springtail community metrics, we pre-selected variables with a known ecological effect on springtail communities (based on expert opinions) and constructed a hypothetical relationship diagram (Extended Data Fig. 9a). Environmental data were very heterogeneous across the springtail studies, so we used globally available climatic and other environmental layers; these included layers bearing climatic (mean annual temperature, temperature seasonality, temperature annual range, mean annual precipitation, precipitation seasonality, precipitation of the driest quarter ${ }^{65}$, aridity index ${ }^{66}$ ), topographic (elevation, roughness ${ }^{67}$ ), vegetative and land cover (aboveground biomass ${ }^{68}$, tree $\operatorname{cover}^{69}$, Net Primary Production, Normalized ratio, $\mathrm{pH}$, clay, sand, coarse fragments, organic carbon, bulk density ${ }^{71}$ ) and human population density $^{72}$.

598 Geospatial global projections. To create global spatial predictions of springtail density, species richness, biomass, and community metabolism, we followed the approach previously used for nematodes ${ }^{18,73}$ that is based on spatial associations of community parameters with global environmental information. A Random Forest algorithm was applied to identify the spatial associations and extrapolate local observations to the global scale ${ }^{18,73}$. After retrieving the environmental variable values for each location, we trained 18 model versions, each with different hyperparameter settings, i.e., variables per split (range: 2 - 7); minimum leaf population (range: 3 - 5). To minimize the potential bias of a single model, we used an ensemble of the top 10 best-performing models, selected based on the coefficient of 
607 determination $\left(\mathrm{R}^{2}\right)$, to create global predictions of each of the community parameters.

608 Geographical regions with climatic conditions poorly represented by our sites and without

609 NPP data were excluded from the extrapolation (e.g., Sahara, Arabian desert, Himalayas). We

610 evaluated our extrapolation quality based on spatial approximations of interpolation versus

611 extrapolation ${ }^{73}$. In this approach, we first determined the range of environmental conditions

612 represented by the observations. Next, we classified all pixels to fall within or outside the

613 training space, in univariate and multivariate space. For the latter, we first transformed the

614 data into principal component space, and selected the first 11 PC axes, collectively explaining

$61590 \%$ of the variation. Finally, we classified pixels to fall within or outside the convex hulls

616 drawn around each possible bivariate combination of these 11 PC axes; pixels that fell

617 outside the convex hulls in $>90 \%$ of cases were masked on the map.

618 To estimate spatial variability of our predictions while accounting for the spatial sampling

619 bias in our data (Fig. 1a) we performed a spatially stratified bootstrapping procedure. We

620 used the relative area of each IPBES ${ }^{74}$ region (i.e., Europe and Central Asia, Asia and the

621 Pacific, Africa, and the Americas) to resample the original dataset, creating 100 bootstrap

622 resamples. Each of these resamples was used to create a global map, which was then reduced

623 to create mean, standard deviation, $95 \%$ confidence interval, and coefficient of variation

624 maps (Extended Data Figs. 4-7).

625 Global biomass, abundance, and community metabolism of springtails were estimated by

626 summing predicted values for each $30 \operatorname{arcsec}_{\text {pixel }}{ }^{18}$. Global community metabolism was

627 recalculated from joule to mass carbon by assuming $1 \mathrm{~kg}$ fresh mass $=7 \times 10^{6} \mathrm{~J}^{75}$, an average

628 water proportion in springtails of $70 \%^{56}$, and an average carbon concentration of $45 \%$

629 (calculated from 225 measurements across temperate forest ecosystems) ${ }^{76}$.

630 Path analysis. To reveal the drivers of springtail communities at the global scale, we

631 performed a path analysis. After filtering the selected environmental variables (see above) 
according to their global availability and collinearity, 13 variables were used (Extended Data

633 Fig. 9b): mean annual temperature, mean annual precipitation (CHELSA database $\left.{ }^{65}\right)$, aridity

634 (CGIAR database ${ }^{66}$ ), soil pH, sand and clay contents combined (sand and clay contents were

635 co-linear in our dataset), soil organic carbon content (SoilGrids database ${ }^{71}$ ), NDVI (MODIS

636 database $^{70}$ ), human population density (GPWv4 database $\left.{ }^{72}\right)$, latitude, elevation ${ }^{67}$, and

637 vegetation cover (woodland, scrub, or agriculture; grasslands were represented as the

638 combination of woodland, scrub, and agriculture absent). Before running the analysis, we

639 performed the Rosner's generalized extreme Studentized deviate test in the EnvStats

640 package $^{77}$ to exclude extreme outliers and we z-standardized all variables (Supplementary $\mathrm{R}$

641 Code).

642 Separate piecewise structural equation models were run to predict density, dry biomass,

643 community metabolism, and local species richness in the lavaan package ${ }^{78}$. To account for

644 the spatial clustering of our data in Europe, instead of running a model for the entire dataset,

645 we divided the data by the IPBES ${ }^{74}$ geographical regions and selected a random subset of

646 sites for Eurasia, such that only twice the number of sites were included in the model as the

647 second most represented region. We ran the path analysis 99 times for each community

648 parameter with different Eurasian subsets (density had $n=723$ per iteration, local species

649 richness had $\mathrm{n}=352$, dry biomass had $\mathrm{n}=568$, and community metabolism had $\mathrm{n}=533$ ). We

650 decided to keep the share of the Eurasian dataset larger than other regions to increase the

651 number of sites per iteration and validity of the models. The Eurasian dataset also had the

652 best data quality among all regions and a substantial reduction in datasets from Eurasia would

653 result in a low weight for high quality data. We additionally ran a set of models in which the

654 Eurasian dataset was represented by the same number of sites as the second-most represented

655 region, which yielded similar effect directions for all factors, but slightly higher variations

656 and fewer consistently significant effects. In the paper, only the first version of analysis is 
presented. To illustrate the results, we averaged effect sizes for the paths across all iterations

661 iterations; Fig. 3).

662

663

\section{Data availability statement.}

664 The data that support the findings of this study are available under CC-BY 4.0 license from

665 Figshare: https://doi.org/10.6084/m9.figshare.16850419; high-resolution maps can be

666 assessed at https://doi.org/10.6084/m9.figshare.16850446.

667

668

\section{Code availability statement}

669 Programming code for the path analysis and the geospatial modelling is available under CC-

670 BY 4.0 from Figshare: https://doi.org/10.6084/m9.figshare.16850419.

671

\section{Methods references}

673 47. Burkhardt, U. et al. The Edaphobase project of GBIF-Germany-A new online soil-zoological 674 data warehouse. Applied Soil Ecology 83, 3-12 (2014).

675 48. Sømme, L. Supercooling and winter survival in terrestrial arthropods. Comparative Biochemistry and Physiology Part A: Physiology 73, 519-543 (1982).

677 49. Fick, S. E. \& Hijmans, R. J. WorldClim 2: new 1-km spatial resolution climate surfaces for global land areas. International Journal of Climatology 37, 4302-4315 (2017).

679 50. R Core Team. R: A language and environment for statistical computing. (R Foundation for $680 \quad$ Statistical Computing, 2019). 
681

682

683

684

685

686

687

688

689

690

691

692

693

694

695

696

697

698

699

700

701

702

703

704

705

706

707

51. Chao, A. \& Jost, L. Coverage-based rarefaction and extrapolation: standardizing samples by completeness rather than size. Ecology 93, 2533-2547 (2012).

52. Oksanen, J. et al. Vegan: community ecology package. R package version 1.17-6. (2011).

53. Bellinger, P. F., Christiansen, K. A. \& Janssens, F. Checklist of the Collembola of the World. http://www.collembola.org/ (2020).

54. Robinson, D. fuzzyjoin: Join Tables Together on Inexact Matching. (2020).

55. Pey, B. et al. A Thesaurus for Soil Invertebrate Trait-Based Approaches. PLoS ONE 9, e108985 (2014).

56. Petersen, H. Estimation of dry weight, fresh weight, and calorific content of various Collembolan species. Pedobiologia 15, 222-243 (1975).

57. Tanaka, M. Ecological studies on communities of soil Collembola in Mt. Sobo, southwest Japan. Japanese Journal of Ecology 20, 102-110 (1970).

58. Ehnes, R. B., Rall, B. C. \& Brose, U. Phylogenetic grouping, curvature and metabolic scaling in terrestrial invertebrates: Invertebrate metabolism. Ecology Letters 14, 993-1000 (2011).

59. Lembrechts, J. et al. Global maps of soil temperature. https://osf.io/pksqw (2021) doi:10.32942/osf.io/pksqw.

60. Bonfanti, J. et al. Intraspecific body size variability in soil organisms at a European scale: implications for functional biogeography. Functional ecology 32, 2562-2570 (2018).

61. Potapov, A. M. et al. Arthropods in the subsoil: Abundance and vertical distribution as related to soil organic matter, microbial biomass and plant roots. European Journal of Soil Biology 82, 8897 (2017).

62. Potapov, A. M., Guerra, C. A. \& van den Hoogen, J. \#GlobalCollembola: site-level database and analyses. Figshare. Dataset. https://doi.org/10.6084/m9.figshare.16850419.v1

63. Wickham, H. ggplot2: elegant graphics for data analysis. (Springer-Verlag, 2009).

64. Mendiburu, F. de. agricolae: Statistical Procedures for Agricultural Research. (2020).

65. Karger, D. N. et al. Climatologies at high resolution for the earth's land surface areas. Scientific Data 4, 170122 (2017). 
66. Zomer, R. J., Trabucco, A., Bossio, D. A. \& Verchot, L. V. Climate change mitigation: A spatial analysis of global land suitability for clean development mechanism afforestation and reforestation. Agriculture, Ecosystems \& Environment 126, 67-80 (2008).

67. Amatulli, G. et al. A suite of global, cross-scale topographic variables for environmental and biodiversity modeling. Scientific Data 5, 180040 (2018).

68. Santoro, M. GlobBiomass - global datasets of forest biomass. (2018) doi:10.1594/PANGAEA.894711.

69. Hansen, M. C. et al. High-Resolution Global Maps of 21st-Century Forest Cover Change. Science 342, 850-853 (2013).

70. Tuanmu, M.-N. \& Jetz, W. A global 1-km consensus land-cover product for biodiversity and ecosystem modelling. Global Ecology and Biogeography 23, 1031-1045 (2014).

71. Hengl, T. et al. SoilGrids250m: Global gridded soil information based on machine learning. PLOS ONE 12, e0169748 (2017).

72. Center for International Earth Science Information Network - CIESIN - Columbia University. Gridded Population of the World, Version 4 (GPWv4): Population Density Adjusted to Match 2015 Revision UN WPP Country Totals. (2016).

73. van den Hoogen, J. et al. A geospatial mapping pipeline for ecologists. http://biorxiv.org/lookup/doi/10.1101/2021.07.07.451145 (2021) doi:10.1101/2021.07.07.451145.

74. IPBES. Summary for policymakers of the global assessment report on biodiversity and ecosystem services of the Intergovernmental Science-Policy Platform on Biodiversity and Ecosystem Services. (2019).

75. Peters, R. H. The ecological implications of body size. (Cambridge University Press, 1983).

76. Potapov, A. M., Tiunov, A. V. \& Scheu, S. Uncovering trophic positions and food resources of soil animals using bulk natural stable isotope composition. Biological Reviews 94, 37-59 (2019).

77. Millard, S. P. EnvStats: An R Package for Environmental Statistics. (Springer, 2013).

78. Rosseel, Y. lavaan: An R Package for Structural Equation Modeling. Journal of Statistical Software 48, 1-36 (2012). 


\section{Acknowledgements}

737 The article is an outcome of the \#GlobalCollembola community initiative that is voluntarily supported by

738 researchers around the world. Data collection and analysis was supported by the Russian Science Foundation

739 (19-74-00154 to A.P.) and by Deutsche Forschungsgemeinschaft (SFB990-EFForTS to S.S.). The following

740 funding bodies provided support for individual contributors: ARC SRIEAS Grant SR200100005 Securing

741 Antarctica's Environmental Future to S.L.C., Slovak Scientific Grant Agency VEGA 1/0346/18 to L.K., RFBR

742 19-516-60002 to N.A.K., Carl Tryggers Stiftelse för Vetenskaplig Forskning and Qatar Petroleum to J.M.A.,

743 BIO 27 (2013-2014)-MAGyP and PICTO 2084 (2012)-ANPCyT to V.B., DAAD-19-10 and MSM200962001 to

744 T.C., grant TE, PN-III-P1-1.1-TE-2019-0358 to C.F., NWO grant 821.01 .015 to O.F., National Natural

745 Sciences Foundation of China No 41471037 and 41871042 to M.G., BIO 27 (2013-2014), MAGyP; PICT 2084

746 (2012), FONCyT to D.F.G., NRF South African National Antarctic Programme grant 110734 to M.G., Natural

747 Resources Canada (NRCan), EcoEnergy Innovation Initiative under the Office of Energy Research and

748 Development, and the Natural Sciences and Engineering Research Council of Canada (NSERC) to I.T.H.,

749 L.A.V. and L.R., Independent Research Fund Denmark grant no. DFF-4002-00384 to M.H., Estonian Science

750 Foundation G9145 to M.I., SA-France bilateral grant to C.J., SA (NRF) / Russia (RFBR) Joint Science and

751 Technology Research Collaboration project no. 19-516-60002 (FRBR) and no. 118904 (NRF) to M.P. and C.J.,

752 European Research Council (ERC), European Union's Horizon 2020 research and innovation programme (grant

753 agreement no. 677232; to N.E.); iDiv, German Research Foundation (DFG-FZT 118, 202548816) to M.J. and

754 N.E., French National Agency of Research (ANR) (JASSUR research project; ANR-12-VBDU-0011),

755 «Ministère de l'Agriculture et de la Pêche» and «Ministère de l'Education Nationale de la Recherche et de la

756 Technologie» (ACTA programme), «Ministère de l'Aménagement du Territoire et de l'Environnement» (Pnetox

757 programme), EU-funded project, ECOGEN QLK5-CT-2002-01666 (www.ecogen.dk), “Agence de

758 l'Environnement et de la Maîtrise de l'Énergie" (BIOINDICATEUR 2, BIOTECHNOSOL), ANDRA and GISFI

759 (www.gisfi.fr) to S.J., GRR SER-BIODIV (Région Normandie, France) to MCha, ESF9258, B02 to A.K.,

760 Fundamental Research Funds for the Central Universities (grant no. 2018CDXYCH0014) to D.L., DFG

761316045089 to J.L., Massey University Research Fund grant to M.A.M., DFG SCHE 376/38-2 to M.M.P., grant

762 from the Austria Academy of Science: Heritage_2020-043_Modeling-Museum to P.Q., Slovak Scientific Grant

763 Agency: VEGA Nos. 1/0441/03 and 1/3267/06 to N.R., Higher Education Commission of Pakistan to M.I.R.,

764 RSF 21-74-00126 to R.A.S., Austrian Federal Government and European Union (Rural Development 2014- 
Development - CNPq (grant no. 152717/2016-1) to B.R.W., 309030/2018-8 to D.Z. and 305426/2018-4 to

\section{Author contributions}

775

776

777

778

779

780

781

782

783

784

785

786

787

Competing interests. Authors have no competing interests to declare.

788

789

Supplementary Information is available for this paper. draft of the manuscript. C.G. and A.M.P. designed and performed the path analysis. J.v.d.H. designed and quality. M.P.B., S.L.C., J.F.P., D.J.R., T.C., N.E., S.S., M.Cha., J.F. and I.T.H. contributed to writing and Z.J.X., R.Y., D.Z., N.E. and S.S. contributed data. All authors contributed to editing of the paper.

A.M.P. designed the study, coordinated the collection, cleaning and standardization of data and wrote the first performed the geospatial modelling. A.B., B.C.B., L.D., L.K., N.A.K., J.F.P. and M.B.Pot. evaluated the data conceptualisation of the manuscript. A.M.P., A.B., M.P.B., S.L.C., L.D., L.K., N.A.K., J.F.P., M.B.Pot., D.J.R., J.M.A., J.I.A., I.B., V.B., S.B., T.B., G.C., M.Cha., T.Che., M.C., A.T.C., J.C., P.Č., A.M.d.1.P, A.D., S.D.F., C.F., J.F., O.F., S.F., E.G., M.G., B.G., D.F.G., M.Gre., I.T.H., C.H., M.H., P.H., M.I., C.J., M.J., S.J., B.S.J., E.J., L.C.I.O.F., O.K.-F., D.B., E.J.K., A.K., E.A.L., D.L., J.L., M.J.L., M.T.M., M.M.M., M.A.M., T.N., I.N., R.O., J.G.P., M.M.P., P.Q., N.R., M.I.R., L.J.R., L.R., R.A.S., S.Sal., E.J.S., N.S., C.S., J.S., Y.B.S., S.K.S., M.S., X.S., W.I.S., A.A.T., M.P.T., M.A.T., M.S.T., M.N.T., A.V.U., L.A.V., L.A.W., B.R.W., D.W., D.Wu., 

made available under aCC-BY-ND 4.0 International license.

791 Materials \& Correspondence. Correspondence and requests for materials should be

792 addressed to A.M.P. 


\section{Extended data}

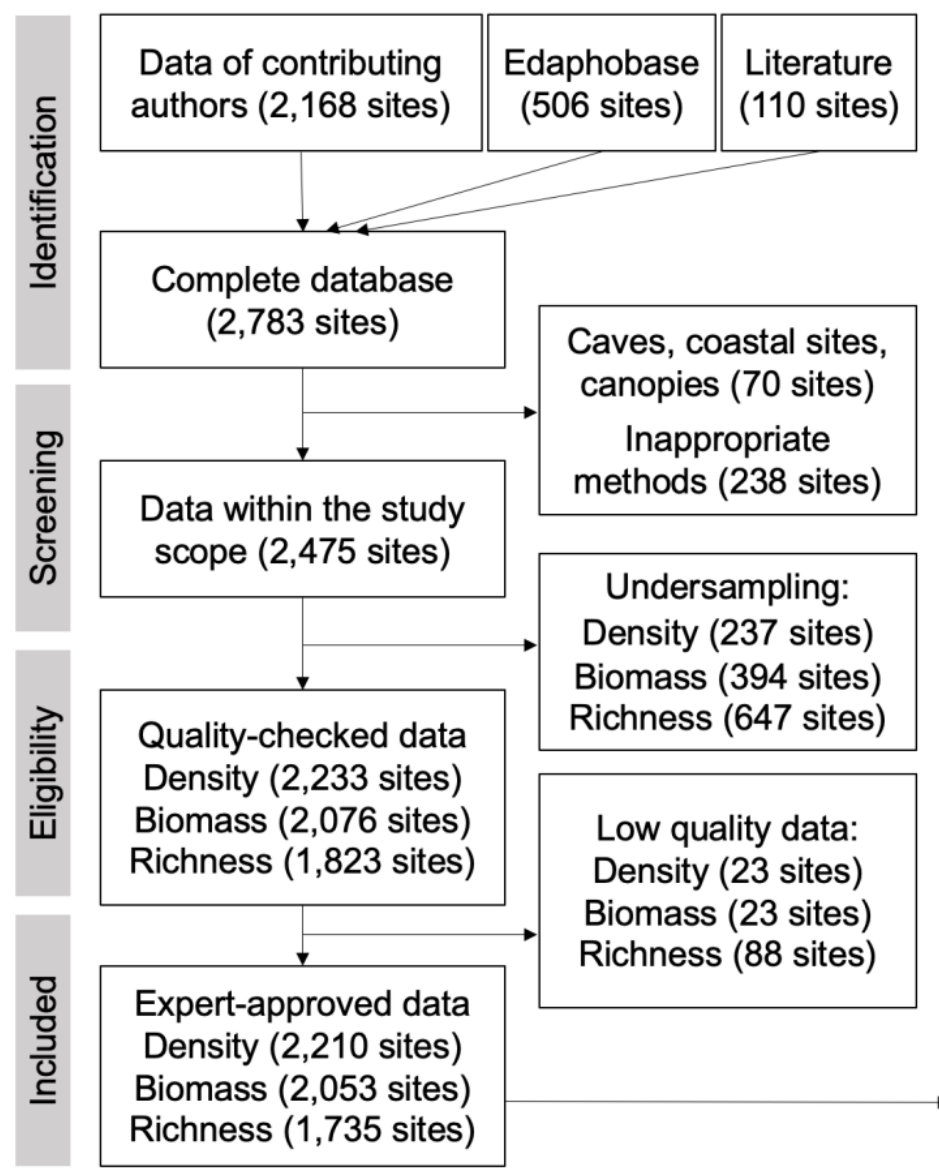

\begin{tabular}{|l|l|l|l|}
\hline \multicolumn{3}{|c|}{ Major data providers } \\
\hline & Sites & Samples \\
\hline Edaphobase & 488 & 77 \\
\hline Anatoly Babenko & 332 & 2,667 \\
\hline $\begin{array}{l}\text { Sophie Joimel, Angélique Renaud, } \\
\text { Céline Pernin and Jérôme Cortet }\end{array}$ & 139 & 4,407 \\
\hline $\begin{array}{l}\text { Lubomír Kováč, Natália Raschmanová } \\
\text { and Peter Čuchta (collaborator: Juha } \\
\text { Alatalo) }\end{array}$ & 136 & 3,239 \\
\hline $\begin{array}{l}\text { Natalia Kuznetsova (collaborators: } \\
\text { Mikhail Potapov, Anna Bokova, Anna } \\
\text { Saraeva) }\end{array}$ & 115 & 10,507 \\
\hline $\begin{array}{l}\text { Stef Bokhorst } \\
\text { includes literature data }\end{array}$ & 176 & 1,955 \\
\hline $\begin{array}{l}\text { Daniel Winkler } \\
\text { Anastasiya Stryuchkova, Stefan }\end{array}$ & 84 & 893 \\
\hline \begin{tabular}{l} 
Pascal Querner \\
\hline Jean-François Ponge
\end{tabular} & 84 & 420 \\
\hline \begin{tabular}{l} 
Viesturs Melecis and Edite Jucevica \\
\hline
\end{tabular} & 1 & 3,300 \\
\hline
\end{tabular}

795 Extended Data Fig. 1 | Flow diagram of data compilation and selection. Major data

796 providers of \#GlobalCollembola whose data were used in the analysis are given in the shaded

797 table on the right side. Providers are ordered based on the number of sites, but exemplar

798 datasets with extensive sampling efforts (number of samples) are given to illustrate the

799 available data. 

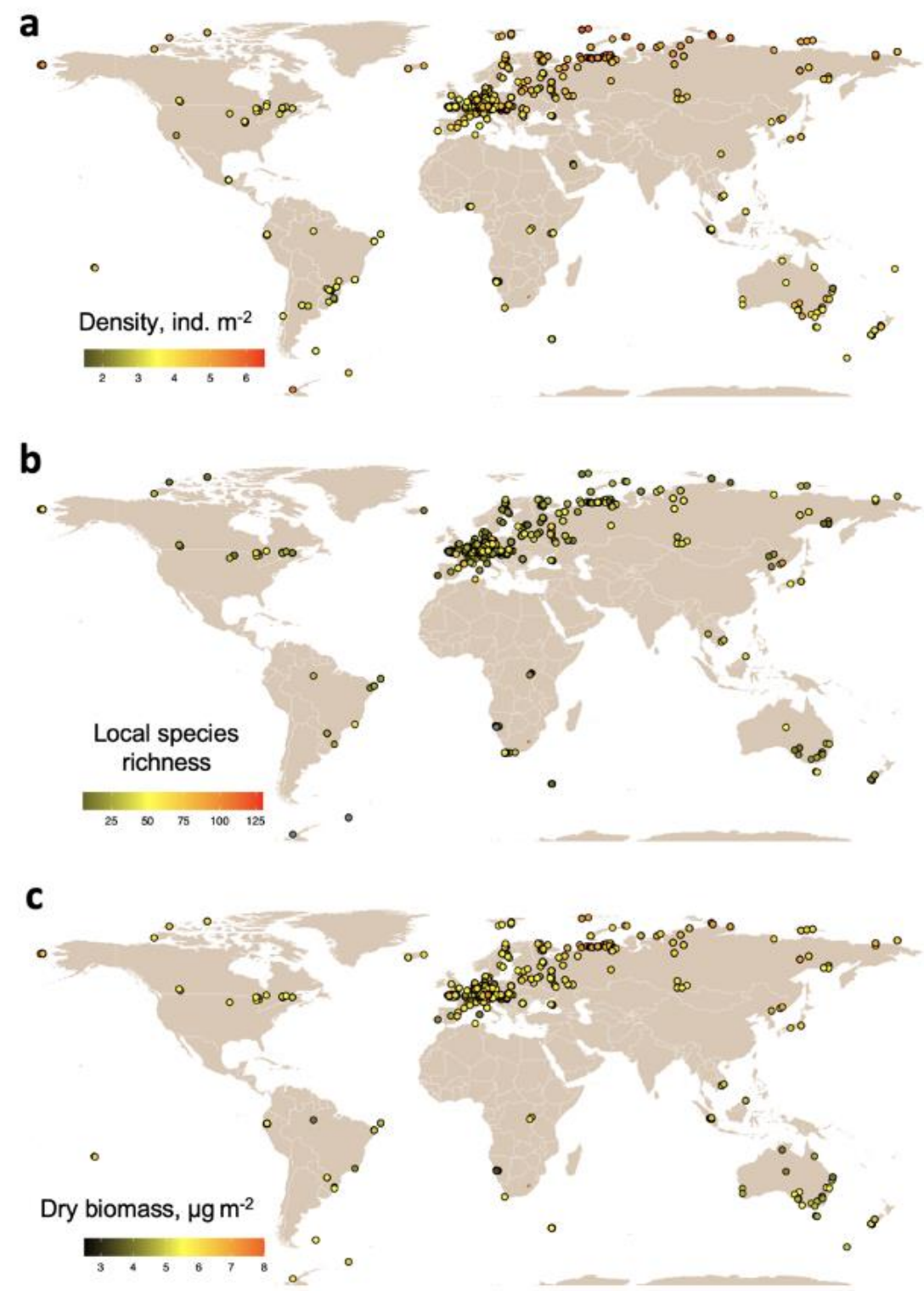

\section{d}

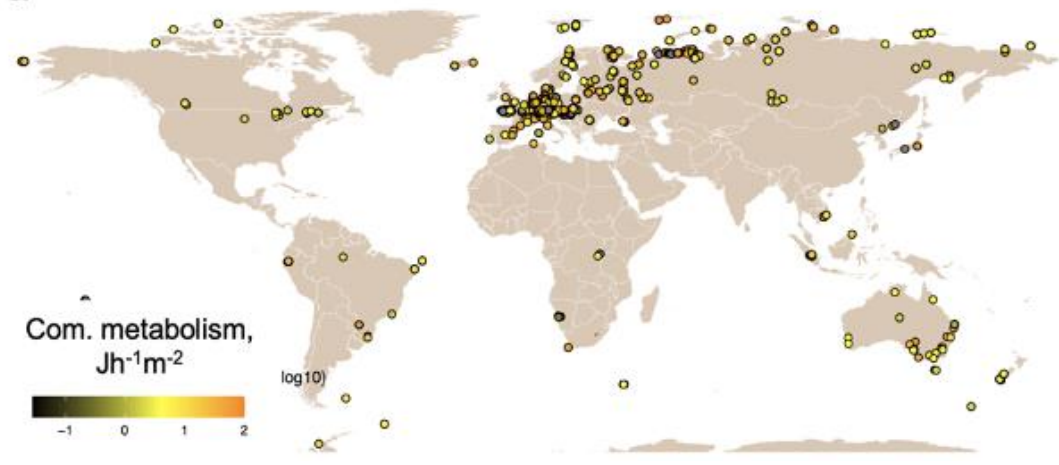

802 Extended Data Fig. 2 | Selected sampling sites that were used in the analysis. a, Density

803 ( $\mathrm{n}=2210), \mathbf{b}$, Local species richness $(\mathrm{n}=1735) ; \mathbf{c}$, Dry biomass $(\mathrm{n}=2053) ; \mathbf{d}$, Community

804 metabolism $(\mathrm{n}=2053)$. Data scales are logarithmic except for local species richness. 
805 Extended Data Table 1 | Regression coefficients used to estimate the dry and fresh body

806 masses of springtail genera based on body lengths. For each genus, the average body mass

$807(M)$ [ $\mu$ g dry weight] was calculated from the average body length $(L)[\mathrm{mm}]$ using the power

808 equation: $M=a^{*} L^{\wedge} b$, where $a$ is the normalisation coefficient and $b$ is the exponent.

809 Abdomen length of Symphypleona was used in the original equations and was assumed to be

$810 \quad 0.83$ of the total body length. Two sets of coefficients coming from two independent

811 studies ${ }^{56,57}$ were used for each morphogroup ( $a_{1}, b_{1}$ and $\left.a_{2}, b_{2}\right)$ and the two estimates of dry

812 body mass were averaged. Fresh body mass was calculated from the resulting average by

813 dividing it by the proportion of the dry weight.

\begin{tabular}{|c|c|c|c|c|c|}
\hline Morphogroup & $\begin{array}{c}\text { Normalisation } \\
\qquad\left(\mathrm{a}_{1}\right)\end{array}$ & $\begin{array}{c}\text { Exponent } \\
\left(b_{1}\right)\end{array}$ & $\begin{array}{c}\text { Normalisation } \\
\text { (a2) }\end{array}$ & $\begin{array}{c}\text { Exponent } \\
\left(\mathrm{b}_{2}\right)\end{array}$ & $\begin{array}{l}\text { Dry weight } \\
\text { proportion }\end{array}$ \\
\hline Entomobryidae & 11.749 & 2.52 & 14.256 & 2.708 & 0.30 \\
\hline $\begin{array}{l}\text { Isotomidae } \\
\text { (small) }\end{array}$ & 6.457 & 2.99 & 5.623 & 2.799 & 0.36 \\
\hline $\begin{array}{l}\text { Isotomidae } \\
\text { (large) }\end{array}$ & 5.623 & 3.28 & 8.427 & 3.223 & 0.36 \\
\hline Onychiuridae & 4.266 & 2.75 & 5.598 & 2.769 & 0.30 \\
\hline $\begin{array}{l}\text { Poduromorpha } \\
\text { (excl. }\end{array}$ & 9.772 & 2.55 & 5.598 & 2.769 & 0.30 \\
\hline Onychiuridae) & & & & & \\
\hline Symphypleona & 190.546 & 3.627 & 39.628 & 3.796 & 0.21 \\
\hline Tomoceridae & 9.204 & 2.744 & 14.256 & 2.708 & 0.25 \\
\hline
\end{tabular}

814 


Polar scrub
Polar grassland
Polar woodland
Temperate woodland
Temperate scrub
Temperate grassland
Temperate agriculture
Tropical agricultur
Tropical woodland

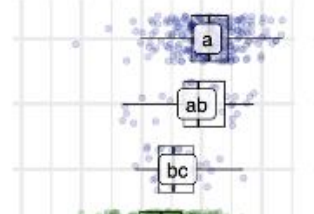

\section{d}
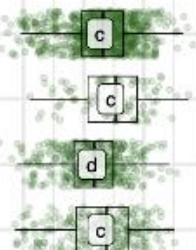

et-

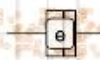

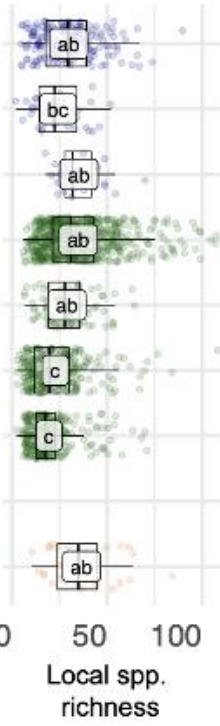
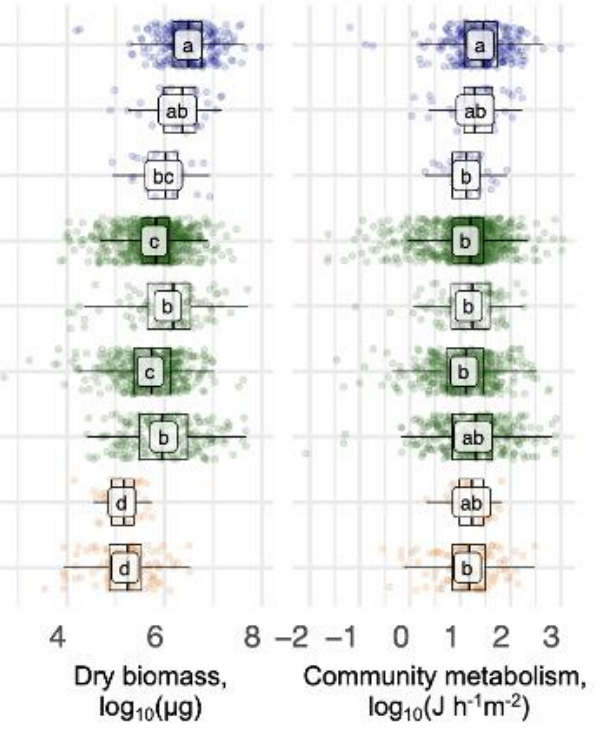

816 Extended Data Fig. 3 | Mean estimates for community parameters in different

817 ecosystem types. Points represent sites, labels represent mean values, means sharing the

818 same letter are not significantly different (Tukey's HSD test for multiple comparisons ${ }^{64}$ ). For

819 ecosystem classification see Methods.

820 

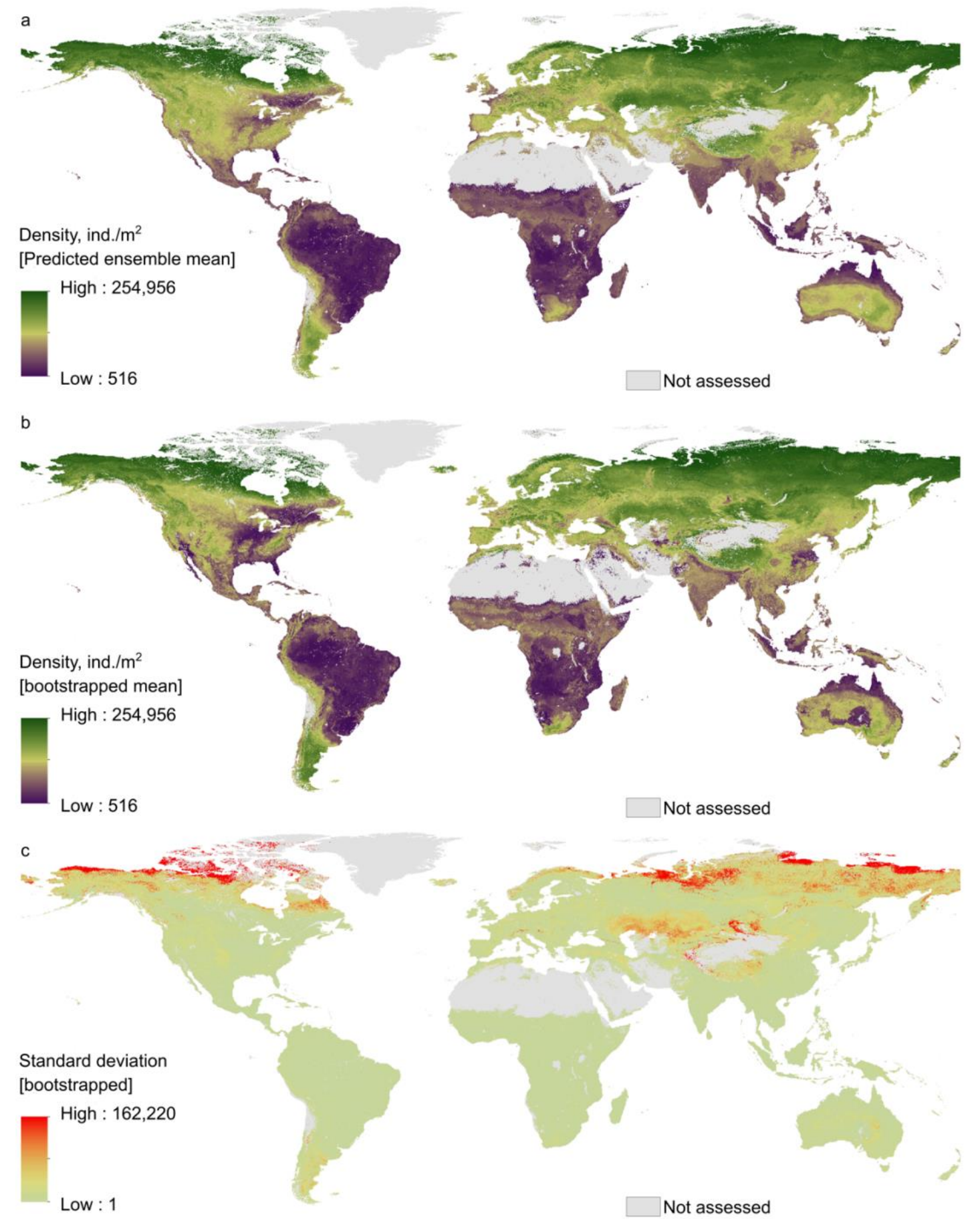

Extended Data Fig. 4 | Global projection of springtail density. Distribution was predicted

with the random forest algorithm (a) based on the entire dataset and (b) using mean

824 prediction after bootstrapping data by continents $\left(\mathrm{R}^{2}=0.57 \pm 0.04\right)$. Green colour identifies

825 hot spots, violet colour cold spots. The bottom map (c) shows the standard deviation across

826 the bootstrapped predictions (red - high, yellow - low). All data were projected at the 30 $\operatorname{arcsec}\left(\right.$ approximately $1 \mathrm{~km}^{2}$ ) pixel scale. 

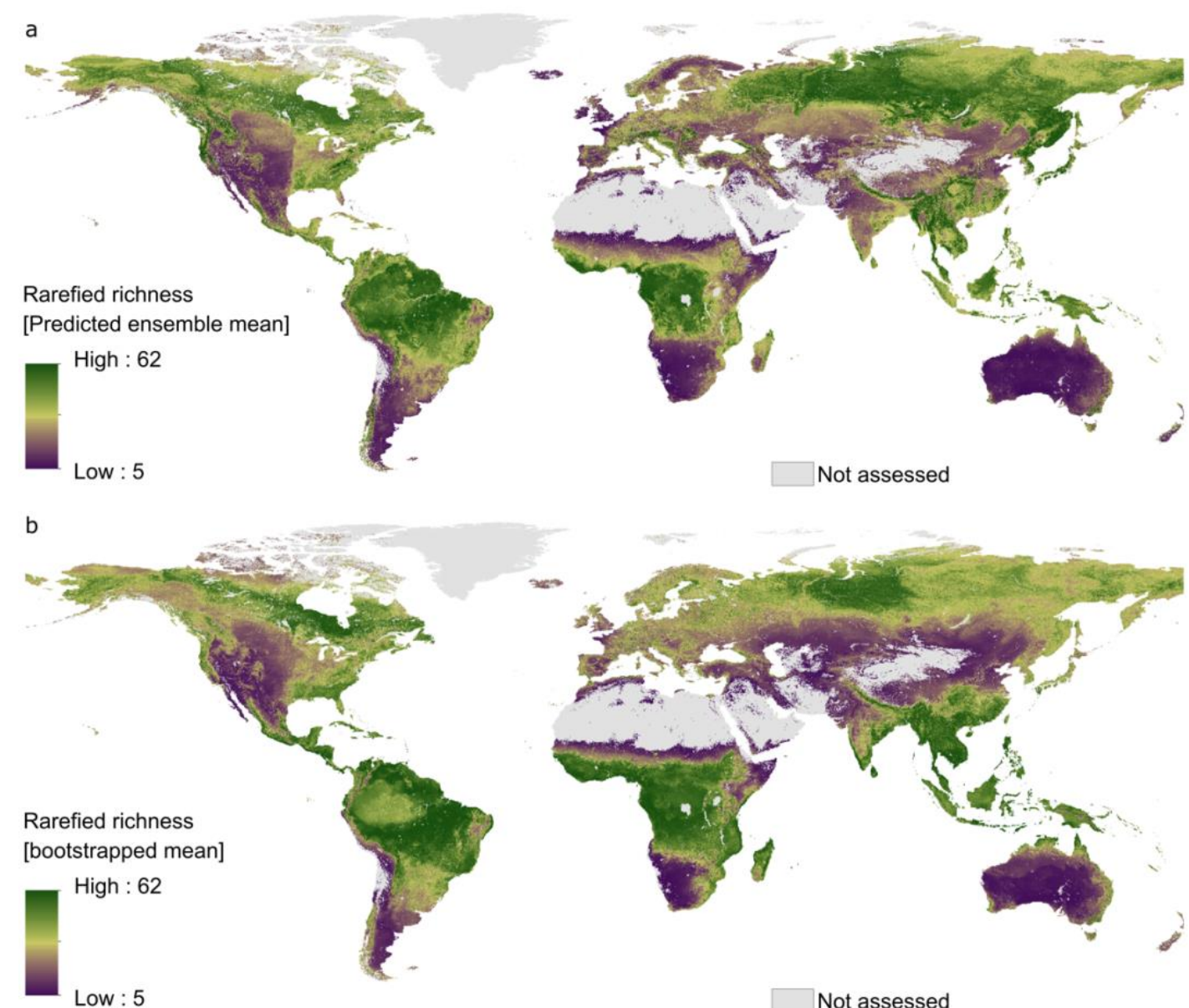

Low : 5
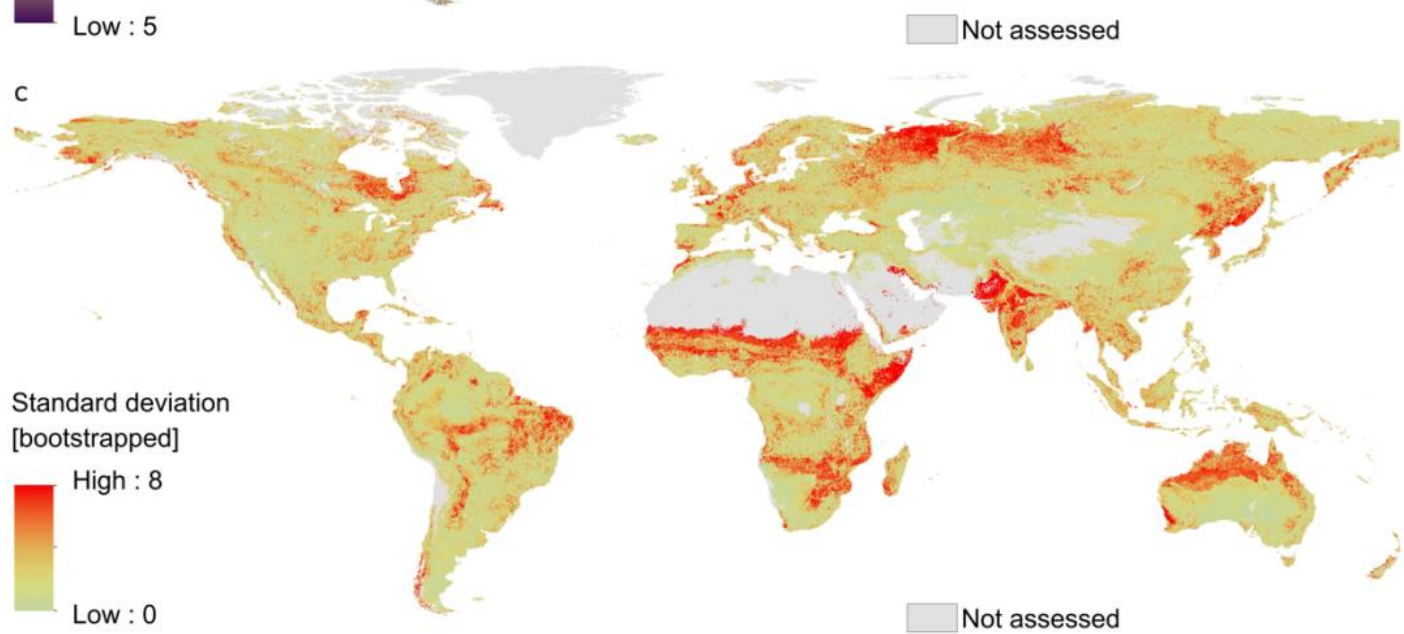

Not assessed

Extended Data Fig. 5 | Global projection of springtail local species richness. Distribution

830 was predicted with the random forest algorithm (a) based on the entire dataset and (b) using

831 mean prediction after bootstrapping data by continents $\left(\mathrm{R}^{2}=0.31 \pm 0.06\right)$. Green colour

832 identifies hot spots, violet colour cold spots. The bottom map (c) shows the standard

833 deviation across the bootstrapped predictions (red - high, yellow - low). All data were

834 projected at the 30 arcsec (approximately $1 \mathrm{~km}^{2}$ ) pixel scale. 

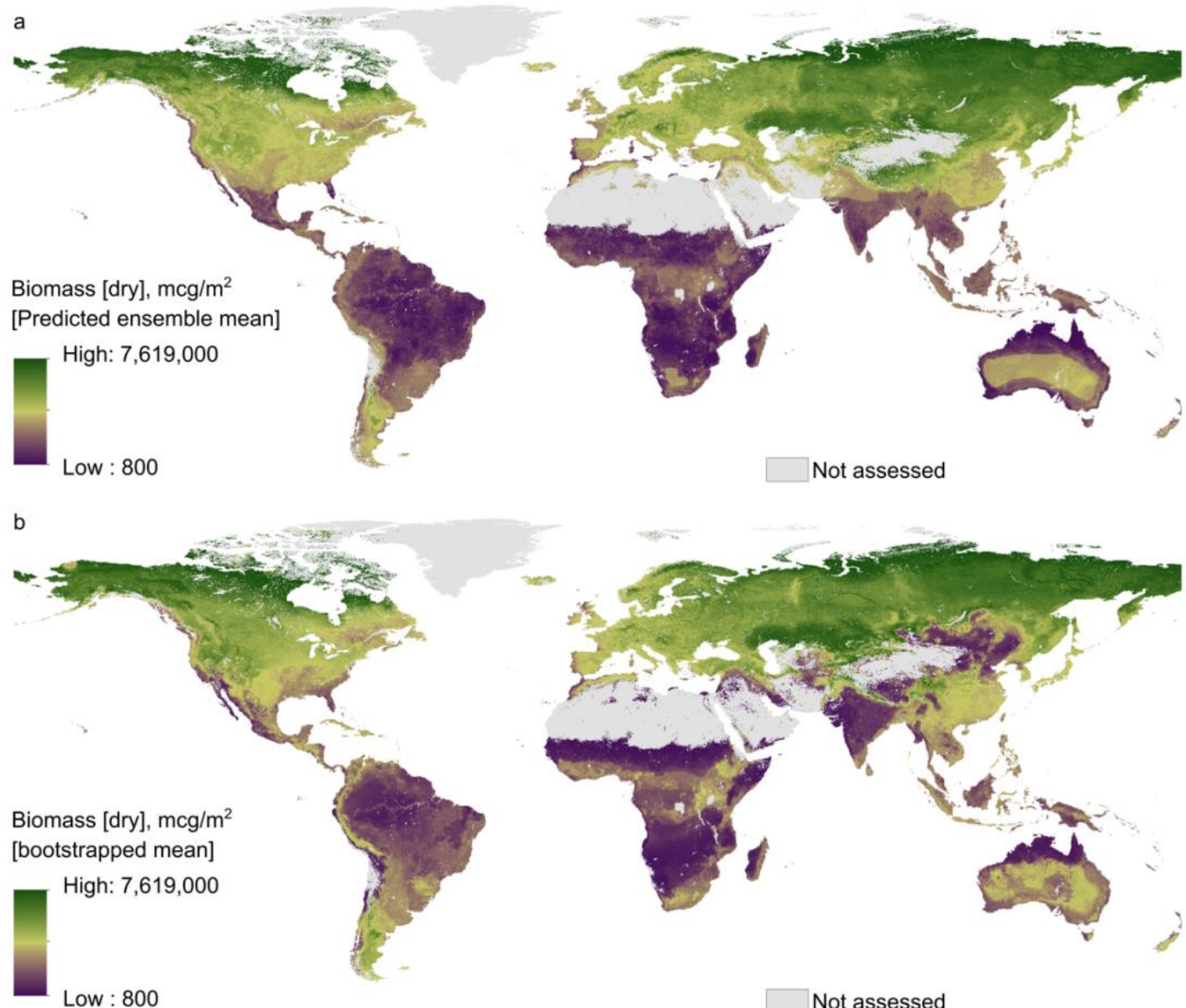

Low : 800
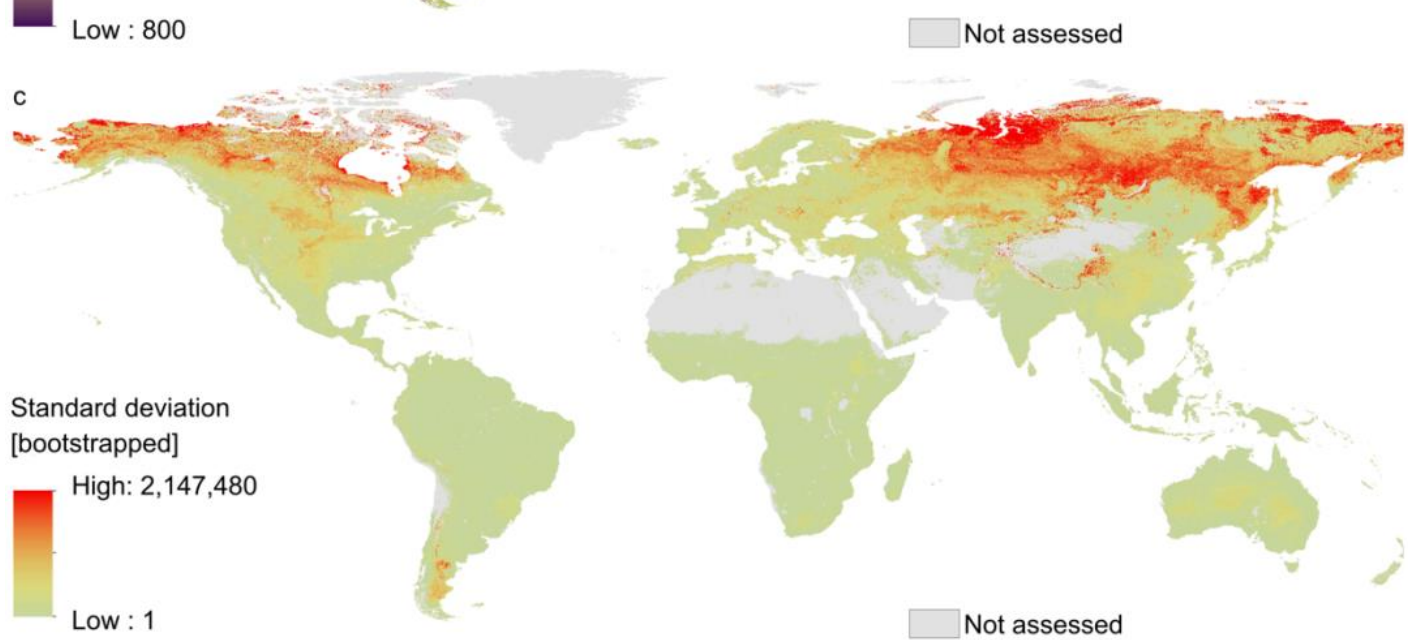

Not assessed

836 Extended Data Fig. 6 | Global projection of springtail biomass. Distribution was predicted

837 with the random forest algorithm (a) based on the entire dataset and (b) using mean

838 prediction after bootstrapping data by continents $\left(R^{2}=0.47 \pm 0.05\right)$. Green colour identifies

839 hot spots, violet colour cold spots. The bottom map (c) shows the standard deviation across

840 the bootstrapped predictions (red - high, yellow - low). All data were projected at the 30

$841 \operatorname{arcsec}\left(\right.$ approximately $1 \mathrm{~km}^{2}$ ) pixel scale. 

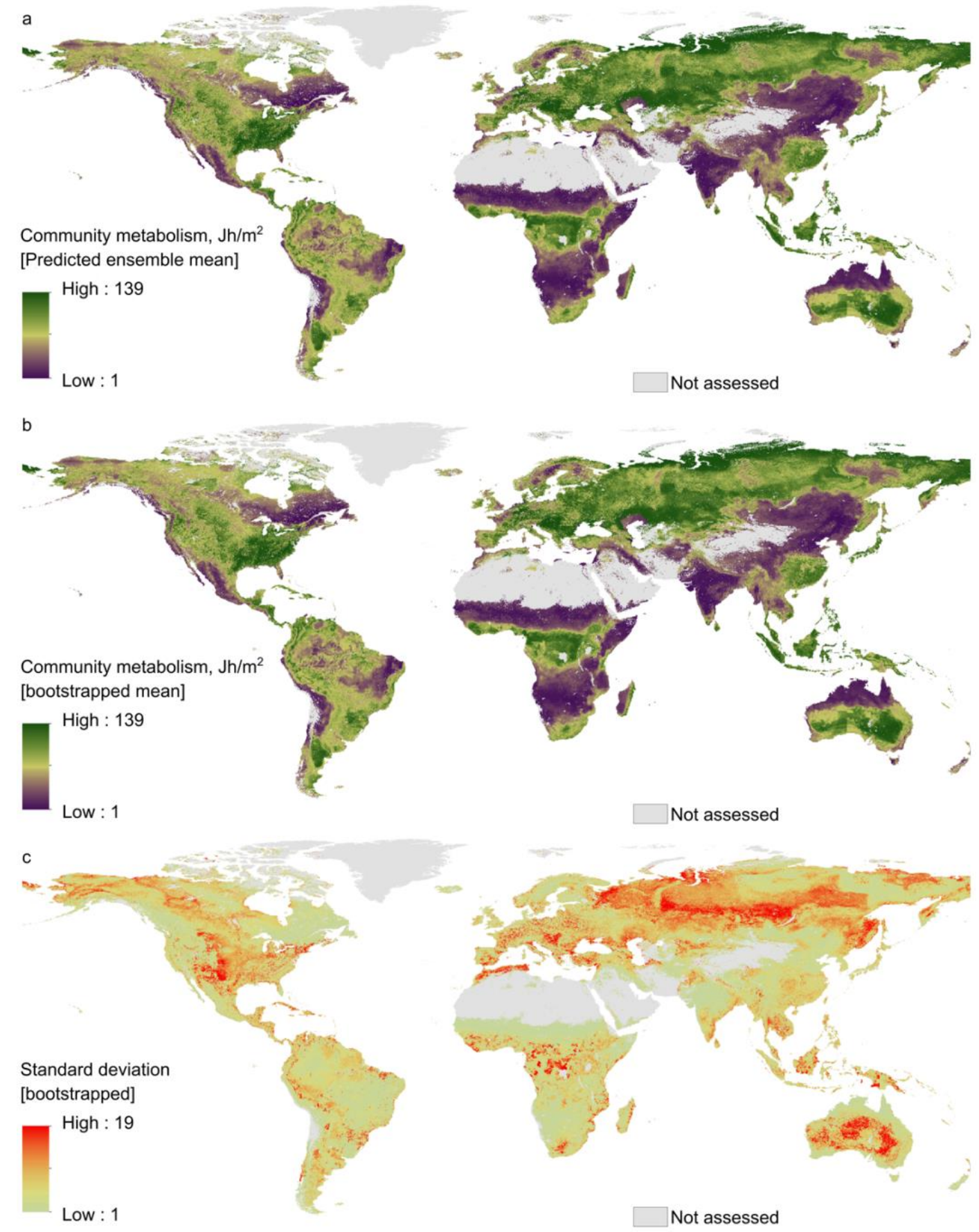

\section{Extended Data Fig. 7 | Global projection of springtail community metabolism.}

844 Distribution was predicted with the random forest algorithm (a) based on the entire dataset

845 and (b) using mean prediction after bootstrapping data by continents $\left(\mathrm{R}^{2}=0.33 \pm 0.09\right)$.

846 Green colour identifies hot spots, violet colour cold spots. The bottom map (c) shows the

847 standard deviation across the bootstrapped predictions (red - high, yellow - low). All data were projected at the 30 arcsec (approximately $1 \mathrm{~km}^{2}$ ) pixel scale. 

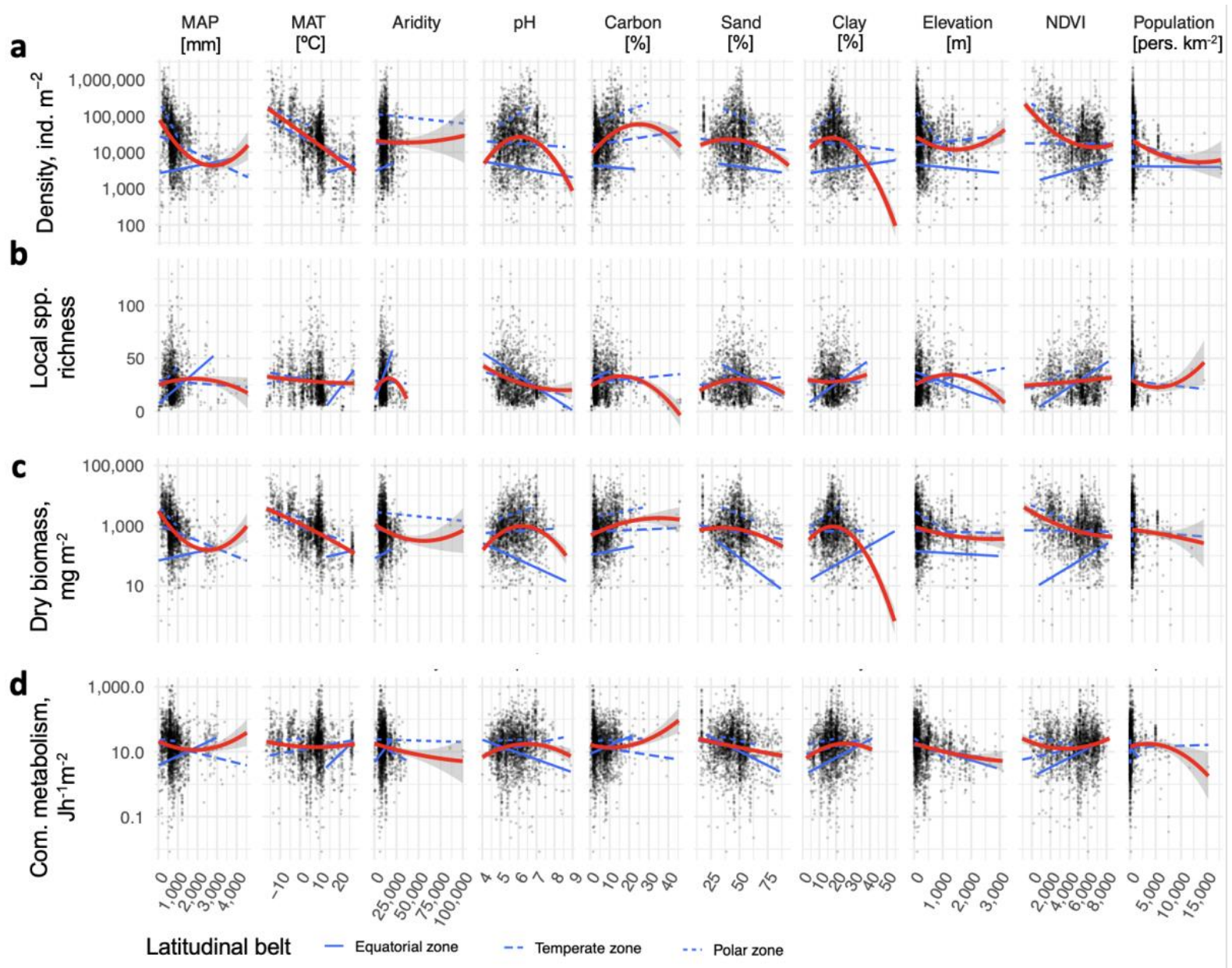

850 Extended Data Fig. 8 | Associations of selected environmental variables with springtail

851 density, local species richness, dry biomass and community metabolism. Quadratic

852 function was used for approximation to illustrate global trends (red line). Blue lines show

853 linear trends in equatorial (solid), temperate (long dash) and polar zones (short dash). 
a

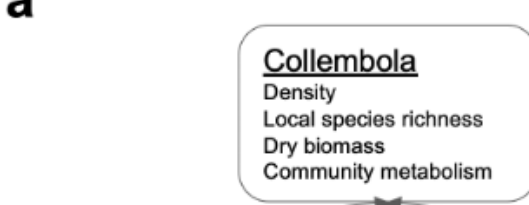

Pre-selected variables

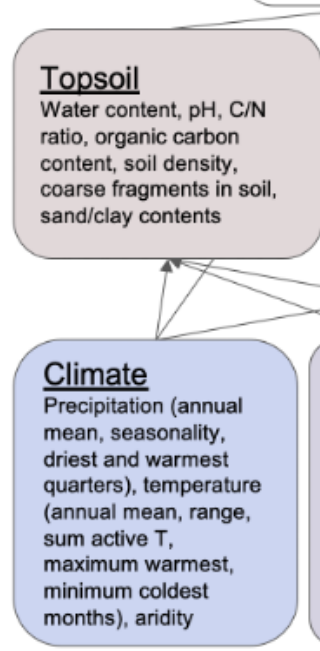

b

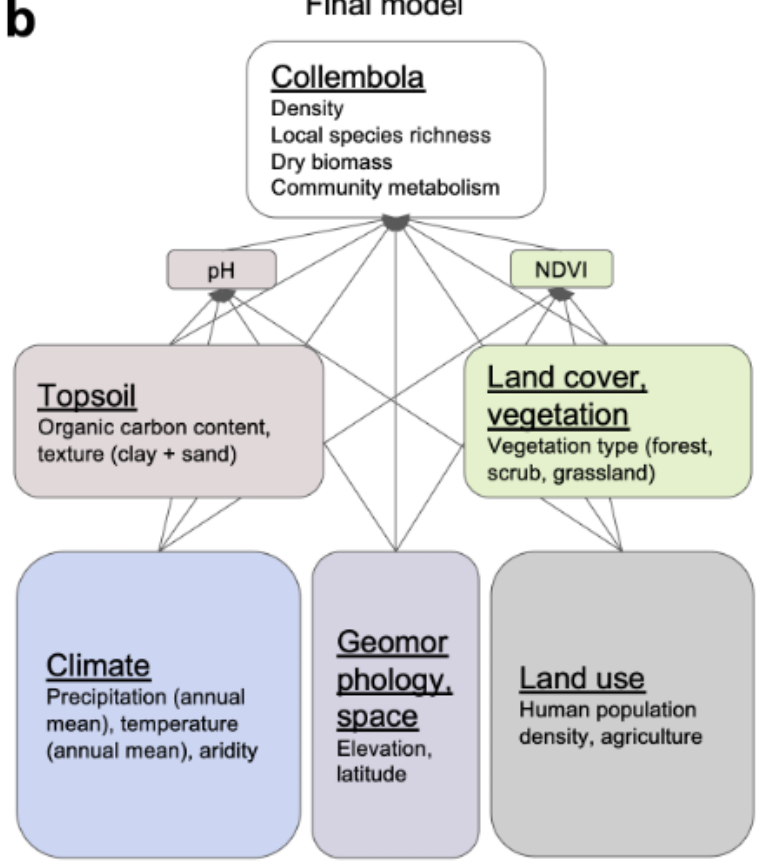

856 Extended Data Fig. 9 | Initial and final relationship diagram in the path analysis. Factors

857 directly and indirectly affecting community parameters of springtails at the global scale were

858 pre-selected based on expert opinion (a). Factors in the final model (b) were further selected

859 according to their global availability and collinear factors were removed. The global

860 distributions of $\mathrm{pH}$ and NDVI (Normalized Difference Vegetation Index) are initially

861 modelled based on other factors, which was accounted for in the final model. 